\title{
Islet-1 Controls the Differentiation of Retinal Bipolar and Cholinergic Amacrine Cells
}

\author{
Yasser Elshatory, ${ }^{1}$ Drew Everhart, ${ }^{2}$ Min Deng, ${ }^{1}$ Xiaoling Xie, ${ }^{1}$ Robert B. Barlow, ${ }^{2}$ and Lin Gan ${ }^{1}$ \\ ${ }^{1}$ Department of Ophthalmology, University of Rochester, Rochester, New York 14642, and ${ }^{2}$ Department of Ophthalmology, State University of New York \\ Upstate Medical Center, Syracuse, New York 13210
}

\begin{abstract}
Whereas the mammalian retina possesses a repertoire of factors known to establish general retinal cell types, these factors alone cannot explain the vast diversity of neuronal subtypes. In other CNS regions, the differentiation of diverse neuronal pools is governed by coordinately acting LIM-homeodomain proteins including the Islet-class factor Islet-1 (Isl1). We report that deletion of Isl1 profoundly disrupts retinal function as assessed by electroretinograms and vision as assessed by optomotor behavior. These deficits are coupled with marked reductions in mature $0 \mathrm{~N}$ - and OFF-bipolar $(>76 \%)$, cholinergic amacrine $(93 \%)$, and ganglion $(71 \%)$ cells. Mosaic deletion of Isl1 permitted a chimeric analysis of "wild-type" cells in a predominantly Isl1-null environment, demonstrating a cell-autonomous role for Isll in rod bipolar and cholinergic amacrine development. Furthermore, the effects on bipolar cell development appear to be dissociable from the preceding retinal ganglion cell loss, because Pou4f2-null mice are devoid of similar defects in bipolar cell marker expression. Expression of the ON- and OFF-bipolar cell differentiation factors Bhlhb4 and Vsx1, respectively, requires the presence of Isl1, whereas the early bipolar cell marker Proxl initially did not. Thus, Isl1 is required for engaging bipolar differentiation pathways but not for general bipolar cell specification. Spatiotemporal expression analysis of additional LIM-homeobox genes identifies a LIMhomeobox gene network during bipolar cell development that includes $L h x 3$ and $L h x 4$. We conclude that Isl 1 has an indispensable role in retinal neuron differentiation within restricted cell populations and this function may reflect a broader role for other LIM-homeobox genes in retinal development, and perhaps in establishing neuronal subtypes.
\end{abstract}

Key words: retina; retinal bipolar cell; transcription factor; differentiation; ERG (electroretinogram); optomotor behavior; amacrine; retinal ganglion cell

\section{Introduction}

Visual processing begins at the level of the retina where a circuit of neurons and glia conveys to the brain light information detected by photoreceptive elements in the retina. The diversity of cell types at each level of this circuit underlies the physiological repertoire of the retina (Masland, 2001). The mechanisms for generating the cellular complexity of the retina are poorly understood. Transcription factors have indispensable roles in the generation of diverse neuronal phenotypes, because genetic manipulation of these factors often leads to an alteration of one or more retinal cell phenotypes (Marquardt et al., 2001; Wang et al., 2001;

\footnotetext{
Received March 18, 2007; revised 0ct. 3, 2007; accepted 0ct. 6, 2007.

This work was supported by National Institutes of Health (NH) Grants EY013426 (L.G.), EY00667 (R.B.B.), and EY017246 (D.E.); NASA (R.B.B.); a Research to Prevent Blindness medical student fellowship (Y.E.); a Fight for Sight Fellowship (D.E.); NIH Training Grant Traineeship T32 NS07489 (Y.E.); Lions of Central New York; and Research to Prevent Blindness grants to the Departments of Ophthalmology at State University of New York (SUNY) Upstate Medical University and the University of Rochester. We thank Drs. Yashuhide Furuta (M. D. Anderson Cancer Center, Houston, TX) for the Six3-cre mouse transgenic line, Debra Bramblett (University of St. Thomas, Houston, TX) for the Bhlhb4 in situ probe, Samuel Pfaff (The Salk Institute, La Jolla, CA) for antibodies against Lhx3 and Lhx4, Robert Chow (University of Victoria, British Columbia, Canada) for an antibody against Vsx1, Francoise Haeseleer (University of Washington, Seattle, WA) for an antibody against CABP5, Rebekah Hafler (SUNY Upstate Medical University, Syracuse, NY) for technical assistance with optomotor behavior measurements, Thurma McDaniel and Karen Bentley for transmission electron microscopic work, and Dr. Rick Libby for helpful discussions.

Correspondence should be addressed to Dr. Lin Gan, 601 Elmwood Avenue, Box 645, Rochester, NY 14642. E-mail: lin_gan@urmc.rochester.edu.

DOI:10.1523/JNEUROSCI.3951-07.2007

Copyright $\odot 2007$ Society for Neuroscience $\quad$ 0270-6474/07/2712707-13\$15.00/0
}

Dyer et al., 2003; Bramblett et al., 2004; Chow et al., 2004; Li et al., 2004; Cheng et al., 2005). For example, bipolar cell generation depends on the homeodomain-containing factor Chx10 and the basic helix-loop-helix (bHLH) factors Mash1 and Math3 (Burmeister et al., 1996; Hatakeyama et al., 2001). Chx10-null or Mash1-Math3 double-null mice display an absence of bipolar cells, whereas gain-of-function studies of Chx10, Mash1, or Math3 do not result in the generation of supernumerary bipolar interneurons, except when Chx10 is ectopically expressed in conjunction with a bHLH gene (Burmeister et al., 1996; Hatakeyama et al., 2001). Targeted disruption of genes downstream of these bipolar cell "specifiers" (Chx10, Mash1 and Math3) affects the differentiation of bipolar subtypes but not their initial generation. Mice deficient of Vsx1, a paired-like homeodomain factor, and of Bhlhb4, an Olig family bHLH factor, display disruptions in the differentiation of OFF-bipolar and rod bipolar subtypes, respectively (Bramblett et al., 2004; Chow et al., 2004; Ohtoshi et al., 2004). The initial generation of OFF-bipolar and rod bipolar cells in these animals is preserved, suggesting that other factors initiate the differentiation programs of bipolar subtypes.

Islet-class factor Islet-1 (Isl1), a LIM-homeodomain transcription factor, has well documented roles in neuronal differentiation (Pfaff et al., 1996). In the retina, Isl1 expression is detected in differentiating ganglion, amacrine, and bipolar cells and is restricted to ON-bipolar, cholinergic amacrine, and ganglion 
cells in the adult (Galli-Resta et al., 1997; Haverkamp et al., 2003b; Elshatory et al., 2007). Because Isl1-null mice die at embryonic day 9.5 (E9.5), before the onset of retinal neurogenesis (Pfaff et al., 1996), the role of Isl1 in retinogenesis remains unknown. Conditional loss of Isl1 in a tissue-specific manner allowed us to study the function of Isl1 in retinal development. In the present study, we used a Six3-promoter-driven Cre recombinase transgenic mouse line in which Cre activity is active in regions giving rise to the neural retina (Furuta et al., 2000). The resulting conditional Isl1 mutants display a significant reduction in bipolar, cholinergic amacrine, and ganglion cells and exhibit a marked visual impairment. The deficits in retinal and visual functions correlate with losses of specific cell types.

\section{Materials and Methods}

Animals. To generate the conditional knock-out allele, $I s l 1^{\text {loxP }}$, we made a targeting construct in which exon 2 of Isl 1 was flanked by two loxP sequences. This targeting construct was linearized with NotI and used for the homologous recombination experiments in W4 embryonic stem (ES) cells (a gift from A. Joyner, New York University, New York, NY). We screened 192 FIAU (1-2' -deoxy-2'-fluoro- $\beta$-D-arabinofuranosyl-5iodouracil)-resistant ES clones by Southern genotyping and identified four positive ES clones. Targeted ES clones were injected into C57BL/6J blastocysts to generate mouse chimeras, and heterozygous Isl1 $1^{\text {loxP/+ }}$ mice were generated in a $129 \mathrm{~S} 6$ and C57BL/6J mixed background. The flippase recognition target-flanked Neo gene cassette in $I s l 1^{\text {loxP/+ }}$ mice was removed using the FLPeR deleter strain to generate the final Isll conditional allele used here (Jax stock number 005703; The Jackson Laboratory, Bar Harbor, ME) (Rodriguez et al., 2000). The generation of Isll ${ }^{\text {lac } Z}$ mice has been described previously (Elshatory et al., 2007). Animal genotypes were determined by standard PCR methods. The PCR primers used to identify the Isl1-lacZ knock-in allele were $5^{\prime}$-AGGGCCGCAAGAAAACTATCC-3' and 5'-ACTTCGGCACCTTACGCTTCTTCT- ${ }^{\prime}$ '. The Isl 1 conditional allele was identified by the following primers: $5^{\prime}$ GGTGCTTAGCGGTGATTTCCT-3' and 5'-GCACTTTGGGATGGTAATTGGAG-3'. Generation of the Six3-cre was described previously, along with its recombination pattern in the R26R reporter line during embryogenesis (Furuta et al., 2000). Cre activity was shown to be restricted to the retina and forebrain of the developing embryo (Furuta et al., 2000). The primers used to identify the Six3-cre allele were $5^{\prime}$ -

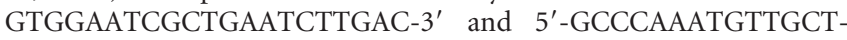
GGATAGT-3'.

5-Bromo-4-chloro-3-indolyl- $\beta$-D-galactopyranoside staining, in situ hybridization, bromodeoxyuridine labeling, and immunohistochemistry. For 5 -bromo-4-chloro-3-indolyl- $\beta$-D-galactopyranoside (X-gal) staining, early postnatal eyes were removed from pups anesthetized on ice. Anterior segments and vitreous were dissected and discarded, leaving the posterior eye cups that were subsequently fixed in $4 \%$ (w/v) paraformaldehyde in PBS, $\mathrm{pH} 7.3$, for $10 \mathrm{~min}$ at $4^{\circ} \mathrm{C}$. Eyes were subjected to X-gal staining as described previously after cyrosectioning (Gan et al., 1999). Frozen sections were stained overnight at $30^{\circ} \mathrm{C}$ in $0.1 \% \mathrm{X}$-gal, $5 \mathrm{~mm}$ potassium ferricyanide, $5 \mathrm{~mm}$ potassium ferrocyanide, and $2 \mathrm{mM} \mathrm{MgCl}_{2}$ in PBS.

For nonradioactive digoxygenin-labeled in situ hybridization, eyes were fixed overnight at $4^{\circ} \mathrm{C}$, washed in PBS several times for $15 \mathrm{~min}$, cryopreserved in $20 \%$ sucrose at $4^{\circ} \mathrm{C}$, and embedded in OCT medium (Tissue-Tek) before cryosectioning at a thickness of $20 \mu \mathrm{m}$. Sections were subsequently processed for in situ hybridization as documented previously (Li and Joyner, 2001).

For bromodeoxyuridine (BrdU) labeling, a $5-10 \mathrm{mg} / \mathrm{ml}$ solution of $\mathrm{BrdU}$ (Sigma, St. Louis, MO) was made in PBS warmed to $37^{\circ} \mathrm{C}$, sterilized through a $0.2 \mu \mathrm{m}$ syringe-driven filter, and injected at a final dose of 0.1 $\mathrm{mg} / \mathrm{g}$ body weight in pups ranging from postnatal day 3 (P3) to P7. Animals were killed $30 \mathrm{~min}$ after injection, and eyes were then harvested for immunohistochemistry. For immunofluorescent labeling, cryosections were blocked in $10 \%$ horse serum in PBST $(0.1 \%$ Triton X-100 in PBS, pH 7.3) for $30 \mathrm{~min}$ at room temperature. After blocking, primary antibodies were applied in PBST containing 3\% horse serum for 12-18 h at $4^{\circ} \mathrm{C}$. Sections were then washed six times and incubated for $1 \mathrm{~h}$ at room temperature with Alexa fluor-conjugated secondary antibodies (Invitrogen, Eugene, OR) used at a dilution of 1:250 in PBST containing 3\% horse serum. Sections were washed three times for $10 \mathrm{~min}$ with PBS. Slides were mounted in Mowiol mounting solution in preparation for microscopy. Sections were visualized using an Olympus (Tokyo, Japan) FluoView confocal laser-scanning system mounted on an Olympus BX50WI upright fluorescence microscope. To quantify the number of different cell type-specific markers on sections of retina, three or more age-matched mice were analyzed for each cell type. A total of 350-700 $\mu \mathrm{m}$ of linear retinal length was counted from each sample and averaged per group. Control and Isl1-null samples used for cell counts were matched for litter and sex. Several genotypes served as controls (see Results), because no histological differences were observed between them. Counts were performed at equivalent retinal eccentricities near the optic nerve head. In all graphs, averages \pm SD are shown. For chimeric analysis of Prkca + rod bipolar cells and ChAT + amacrine cells in Isll-null retinas, $\sim 2-8 \mathrm{~mm}$ of linear retinal length from a composite of at least three mutant animals were scored for residual rod bipolar and cholinergic amacrine cells while blinded to whether Isll expression was present or not. Fifty representative rod bipolar and 35 representative cholinergic amacrine cells were analyzed. Isl1-positive or -negative status was assessed, and the numbers of single- and double-immunopositive cells were scored. For morphometry of rod bipolar cells in control, Isl1-null, and Pou4f2-null retinas (see Fig. $2 J$ and supplemental Fig. 7, available at www.jneurosci.org as supplemental material), $10 \mu \mathrm{m}$ compressed $Z$-stacks were collected of rod bipolar cells after anti-Prkca immunolabeling in the three different genotypes. $Z$-stacks encompassed all the neuronal processes of the cells analyzed. The two-dimensional projections of representative cells were traced in Photoshop, and morphometric analysis of the areas of dendritic and terminal arborizations as well as of process length were performed using NIH ImageJ software.

The following antibodies were used for immunofluorescent labeling: rabbit anti-activated caspase-3 (1:200; R \& D Systems, Minneapolis, $\mathrm{MN})$; rabbit anti- $\beta$-galactosidase (1:300; AB986; Chemicon, Temecula, CA); goat anti-Bhlhb5 (1:300; SC-6045; Santa Cruz Biotechnology, Santa Cruz, CA); mouse anti-BrdU (1:50; Developmental Studies Hybridoma Bank, Iowa City, IA); rabbit anti-calcium-binding protein 5 (CABP5; 1:1000; courtesy of Dr. F. Haeseleer, University of Washington, Seattle, WA); mouse anti-calbindin (1:3000; C9848; Sigma); rabbit anticalretinin (1:2000; PC254L; Calbiochem, La Jolla, CA); goat anti-ChAT (1:50 or 1:100; AB144P; Chemicon); mouse anti-Cdkn1b (1:200; 610241; BD Biosciences, San Diego, CA); mouse anti-Pax6 (1:200; catalog \#Pax6; Developmental Studies Hybridoma Bank); sheep anti-Chx10 (1:1000; X1180P; Exalpha Biologicals, Watertown, MA); rabbit anti-Go $\alpha$ (1:1000; 07-634; Upstate, Lake Placid, NY); mouse anti-GAD65 (glutamate decarboxylase $65 \mathrm{kDa}$; 1:200; BD Biosciences); mouse anti-Isl1/2 (1:200; cata$\log \# 39.4 \mathrm{D} 5$; Developmental Studies Hybridoma Bank); rabbit anti-Lhx3 and Lhx4 (1:2500 each; courtesy of Dr. S. Pfaff, The Salk Institute, La Jolla, CA); rabbit anti-phosphorylated histone H3 (pH3; 1:400; Santa Cruz Biotechnology); mouse anti-Pou4f1 (1:1000; SC-8429; Santa Cruz Biotechnology); goat anti-Pou4f2 (1:200; Santa Cruz Biotechnology); rabbit anti-Prkca (1:7000; P4334; Sigma); rabbit anti-Prox1 (1:5000; PRB-238C; Covance, Princeton, NJ); rabbit anti-Recoverin (1:500; AB5585; Chemicon); rabbit anti-tyrosine hydroxylase (TH; 1:200; Chemicon); rabbit anti-vesicular glutamate transporter (vGlut1; 1:1000; 135 303; Synaptic Systems, Göttingen, Germany); and rabbit anti-Vsx1 (1:200; courtesy of Dr. R. Chow, University of Victoria, British Columbia, Canada).

Measurement of retinal function. Eight to 12-week-old mice of both sexes were assessed via the electroretinogram (ERG) as described previously (Umino et al., 2006b). Mice were dark adapted overnight in a light-proof cage. The following day, under dim red light, mice were anesthetized with Nembutal $(60 \mathrm{mg} / \mathrm{kg}$ ), pupils were dilated with Tropicamide, and corneas were kept moist with $0.3 \%$ glycerin $/ 1 \%$ propylene glycol. Body temperature was maintained at $37^{\circ} \mathrm{C}$ via a heating pad and monitored via a rectal thermometer throughout the recording session. ERGs were recorded with a Burian Allen electrode (0.3-1000 Hz; Hansen 
Ophthalmic Development Laboratory, Coralville, IA) in response to 10 $\mathrm{ms}$ light-emitting diode flashes $(520 \mathrm{~nm})$ delivered at a variety of light intensities. For maximal light intensity [ $\log \mathrm{I}=0$ (see Fig. $8 A, B$ )], the light intensity at the surface of the cornea was $66 \mathrm{~cd} \mathrm{~m}^{-2}\left(0.9 \times 10^{-5}\right.$ photons $\mu \mathrm{m}^{-2}$ ). b-wave amplitudes were measured from the trough of the corneal negative a-wave to the peak of the corneal positive b-wave. Intensity response data were fitted with the Hill equation.

Measurement of visual function. Visual acuity and contrast sensitivity of mice were assessed by observing their optomotor behavior using a two-alternative forced-choice paradigm as described previously (Umino et al., 2006a,b). Briefly, a mouse was placed on a pedestal in the center of a square array of monitors that displayed a rotating sinusoidal grating $(12 \%)$ at photopic luminance levels $\left(70 \mathrm{~cd} \mathrm{~m}^{-2}\right)$. The observer monitored the mice via a video feed from the testing chamber. Mice that detected the rotating pattern generally exhibited an optomotor response consisting of a reflexive head movement in the direction of pattern rotation. In each trial, a randomized protocol selected the direction of grating rotation, clockwise or counterclockwise, and the observer determined the direction of rotation based on the animal's optomotor response to a $5 \mathrm{~s}$ stimulus initiated by the observer. An automated staircase paradigm adjusted the spatial frequency and/or contrast of the rotating pattern on subsequent trials until a threshold was achieved (70\% correct responses by the observer). Acuity was defined as the highest spatial frequency (100\% contrast) yielding a threshold response, and contrast sensitivity was defined as 100 divided by the lowest percentage contrast (pattern of 0.128 cycles/degree) yielding a threshold response. Observers were "double blind" (i.e., they were unaware of the direction of pattern rotation and the animal being tested, its genotype, sex, age, and previously recorded thresholds). Each measure of acuity and contrast sensitivity was the mean of four to seven trials per mouse. Three Isll-null mice and three control mice were tested. ERG and behavioral controls consisted of more than one genotype, including a mouse that was compound heterozygous for the Isll conditional and the Isl1-lacZ knock-in alleles. In both the ERG and visual acuity tests, animals of the different control genotypes performed similarly, as was expected based on immunohistochemistry experiments, which revealed that heterozygotes were phenotypically indistinguishable from wild types (data not shown) (Elshatory et al., 2007). However, in the contrast sensitivity measurement, although the two mice homozygous for the conditional Isll alleles had threshold contrast measures of $\sim 7 \%$, the mouse possessing a lac $Z$ knock-in allele and a conditional Isl 1 allele had a contrast sensitivity intermediate to Isll-null mice and the other controls at $\sim 40 \%$.

Transmission electron microscopy. Retinal samples isolated from three animals of each genotype were prepared by bisecting eyes while in fixative ( $6 \%$ glutaraldehyde in $0.1 \mathrm{~m}$ cacodylate buffer with $1 \mathrm{~mm} \mathrm{CaCl}_{2}$ ). Tissues were then postfixed in osmium tetroxide, dehydrated in ethanol, embedded in Epon plastic, and stained with uranyl acetate en bloc. Onemicrometer-thick sections were cut using the Reichert-Jung Ultracut E ultramicrotome and counterstained with toluidine blue. Subsequently, $70 \mathrm{~nm}$ sections were cut and stained further with $2 \%$ uranyl acetate and Reynold's lead citrate. Grids were viewed on a Hitachi (Tokyo, Japan) H7100 transmission electron microscope. Digital images were acquired using a MegaView III digital camera.

\section{Results}

\section{Conditional inactivation of Isl 1 in the retina}

The Isl1-conditional knock-out animal was generated to determine the function of Isl1 in retinal neurogenesis in vivo while circumventing the embryonic lethality of conventional Isl1 knock-out animals (Pfaff et al., 1996). Two modified alleles were generated to study the function of Isl1 in retinal development: a lacZ knock-in allele and a conditional allele. Homozygous Isl1conditional mice, Isl1 ${ }^{\operatorname{lox} P / \operatorname{lox} P}$, were mated to either Six3-cre; Isl $1^{\text {loxP/+ }}$ or Six3-cre; Isl1 $1^{\text {lacz/+ }}$ compound heterozygotes to yield Isl1-conditional knock-outs, Six3-cre; Isl1 ${ }^{\text {loxP/lacZ }}$ and Six3-cre; Isl1 ${ }^{\text {loxP/loxP }}$ mice (Isl1-null mice hereafter). The recombination pattern of Six3-cre in the developing forebrain and retina has been described previously, where it is detectable in the retina starting at E9.5 (Furuta et al., 2000). More detailed analysis of the recombination pattern of Six3-cre in the mature retina suggested it may incompletely excise target genes of interest. For example, we detected Isl1 + cells in the mature retina that were negative for Six3-cre lineage (supplemental Fig. 1, available at www.jneurosci. org as supplemental material). Furthermore, Six3-cre resulted in extensive recombination in multiple hypothalamic nuclei as well as other forebrain structures (supplemental Fig. 1, available at www.jneurosci.org as supplemental material). Nevertheless, Isl1-null mice were viable at birth but routinely had a reduced body size throughout the first postnatal week compared with Six3-cre; Isl1 ${ }^{\text {loxP/+}}, I s l 1^{\text {loxP/loxP }}$, or Isl1 $1^{\text {loxP/lacZ }}$ (control mice hereafter). When weighed at 10 weeks, Isl1-null females weighed $20 \%$ less than littermate female controls (95\% confidence interval, $2.0724 \mathrm{~g}<\operatorname{diff}<7.2976 \mathrm{~g} ; n=4)$. Additionally, Isl1-null mice were observed at $65 \%$ of the frequency expected from a normal Mendelian ratio, indicating that the loss of Isl1 outside of the retina likely resulted in an embryonic lethal phenotype with incomplete penetrance $\left(\chi^{2}=11.69,3 ; n=185 ; p<0.01\right)$.

\section{Isl1-null mice display retinal hypoplasia}

Although the gross lamination of the developing and adult retina was normal in $I s l 1$-null animals (Fig. $1 A-F$ ), there was considerable thinning of the ganglion cell layer (GCL) and inner nuclear layer (INL) compared with control littermates (Fig. 1C,F). Indeed, a $71 \%$ reduction in retinal ganglion cells (RGCs) was observed based on immunolabeling for Pou4f1 (supplemental Fig. 2, available at www.jneurosci.org as supplemental material) (average number of Pou4f1 + cells \pm SD: controls: $35 \pm 7, n=3$; Isl1-nulls: $10 \pm 2, n=3 ; p<0.01$, Student's $t$ test). Pou4f1 identifies RGCs in mouse retina (Xiang et al., 1995). Hypocellularity of the INL was observed by P8 and was still present at P27, when the retina reaches maturity (Fig. $1 B, C, E, F$ ). To determine the degree to which changes in proliferation might contribute to this INL hypocellularity, BrdU incorporation from P3 to P7 was assessed (Fig. 1M,N and supplemental Fig. 8, available at www. jneurosci.org as supplemental material). BrdU incorporation at the time point corresponding to peak bipolar cell genesis (P3) showed that the number of cells undergoing $S$ phase during the period sampled was not significantly different (average number of BrdU+ cells \pm SD: controls: $112 \pm 10, n=3$; Isl1-nulls: $121 \pm$ $18, n=3 ; p=-4.5$, Student's $t$ test). Also, anti-pH3 immunolabeling at $\mathrm{P} 3$ revealed that the number of progenitors undergoing mitosis at this stage was significantly greater in Isl1-nulls (average number of $\mathrm{pH} 3+$ cells $\pm \mathrm{SD}$ : controls: $14 \pm 2, n=3$; Isl1-nulls: $31 \pm 8, n=3 ; p<0.05$, Student's $t$ test; data not shown). The proliferation of late retinal progenitors at P5-P7, which give rise almost exclusively to bipolar cells, photoreceptors, and Müller glia (Young, 1985), was also not diminished in Isl1-null retinas (supplemental Fig. 8, available at www.jneurosci. org as supplemental material). Thus, the lack of significant decreases in BrdU labeling from P3 to P7 (Fig. 1 and supplemental Fig. 8, available at www.jneurosci.org as supplemental material) suggests that reduced progenitor cell proliferation is unlikely to underlie the reduction in INL thickness in the Isl1-null retina.

At 4 weeks of age, mutant retinas exhibited markedly fewer Isl1 + cells in the INL and GCL (supplemental Fig. 3, available at www.jneurosci.org as supplemental material). The residual Isl1+ cells in the Isl1-null retinas colocalized with Isl1-lacZ expression (supplemental Fig. 3, available at www.jneurosci.org as supplemental material), suggesting that the remaining Isl1 immunoreactivity corresponds to Isl1 expression. Isl1-lacZ reporter expression was also markedly reduced at 4 weeks of age (supplemental 
Fig. 3, available at www.jneurosci.org as supplemental material), which might be explained by a failure of these cells to develop, cell death, or downregulation of the expression of the reporter gene.

To explore the loss of Isl1-lacZ reporter expression in Isl1-null retinas, a time course of early postnatal retinas spanning the first postnatal week was analyzed (Fig. 1G-L). X-gal histochemistry in control and Isl1-null retinas demonstrated that at P6, bipolar cells were generated and activated the Isll promoter to similar extents in the Isl1-null retina (Fig. $1 K$, black arrowhead) compared with control (Fig. $1 \mathrm{H}$, black arrowhead). At P7, a marked divergence in reporter-positive cells within the bipolar cell layer arose between Isl1-null and control retinas (Fig. $1 I, L$, black arrowheads). Assays of cell death spanning P3-P8 failed to reveal significantly greater levels of cell death either by anti-activated caspase-3 immunohistochemistry (supplemental Fig. 6, available at www.jneurosci.org as supplemental material, and data not shown), or by counts of pyknotic nuclei or terminal dUTP nick-end labeled cells. Thus, cell death is unable to account for the precipitous loss of reporter gene expression in Isl1-null mice (Fig. 1I,L).

Isl1 is required for the differentiation of multiple bipolar subtypes

The high level of Isl1 expression within subsets of INL neurons, together with a marked reduction in INL thickness, suggests that Isl1 retinal inactivation leads to an absence or degeneration of INL neurons or glia. Because four of the seven major cell types in the mouse retina reside in the INL, immunolabeling experiments using cell type-specific markers were performed to gauge the development of the major neuronal and glial cells in the INL of Isl1-null and control retinas. Calbindin, Pax6, and Cdkn1b immunostaining were used to gauge the development of horizontal, amacrine, and Müller cells, respectively (Pasteels et al., 1990; Pochet et al., 1991; Dyer and Cepko, 2001; Marquardt et al., 2001). With the exception of a modest $27 \%$ reduction in Müller cells in the Isl1-null retina (average number of Cdkn1b+ cells \pm SD: controls: $41 \pm 5, n=3$; Isl1-nulls: $30 \pm 4, n=3 ; p<$ 0.05 , Student's $t$ test), other major INL cell types were not significantly changed (supplemental Fig. 2, available at www.jneurosci.org as supplemental material). Pan-bipolar cell markers, such as Prox 1 and Chx10, were used to gauge the numbers of developing and mature bipolar cells between P6 and P27. Prox1 is also expressed by horizontal cells and a subpopulation of amacrine cells (Dyer et al., 2003). Prox1 + bipolar cells lie between similarly labeled horizontal and amacrine cells. Prox 1 immunostaining in Isl1-null revealed normal positioning of horizontal, bipolar, and
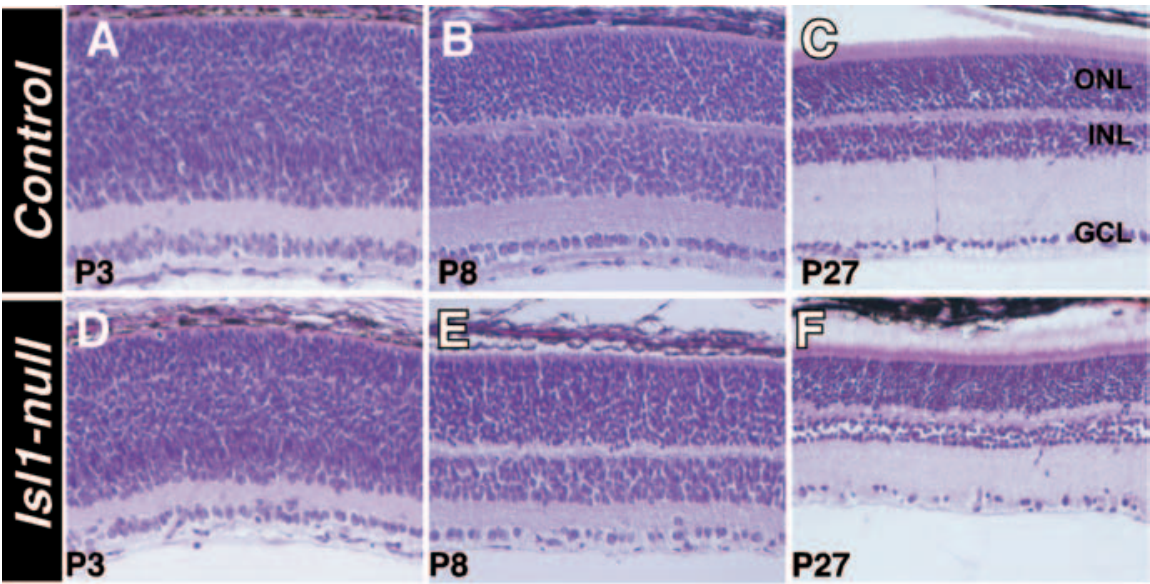

P27
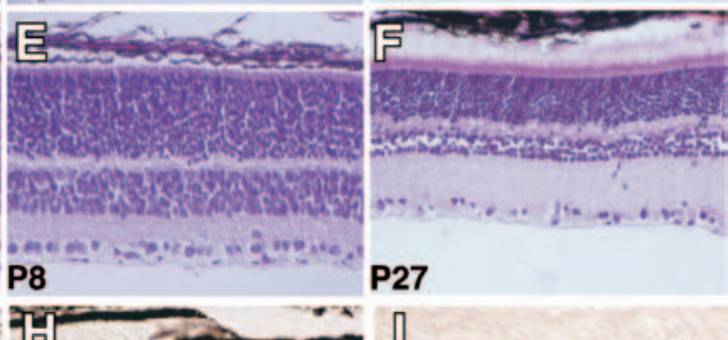

P27
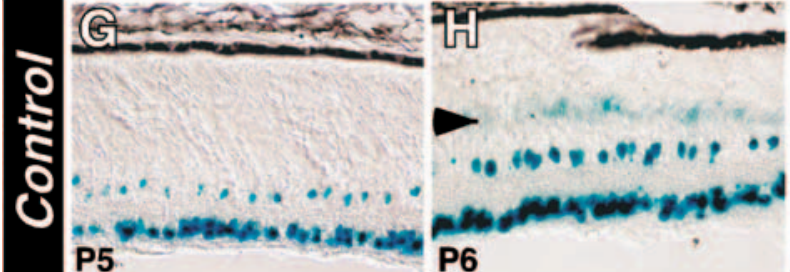

[1
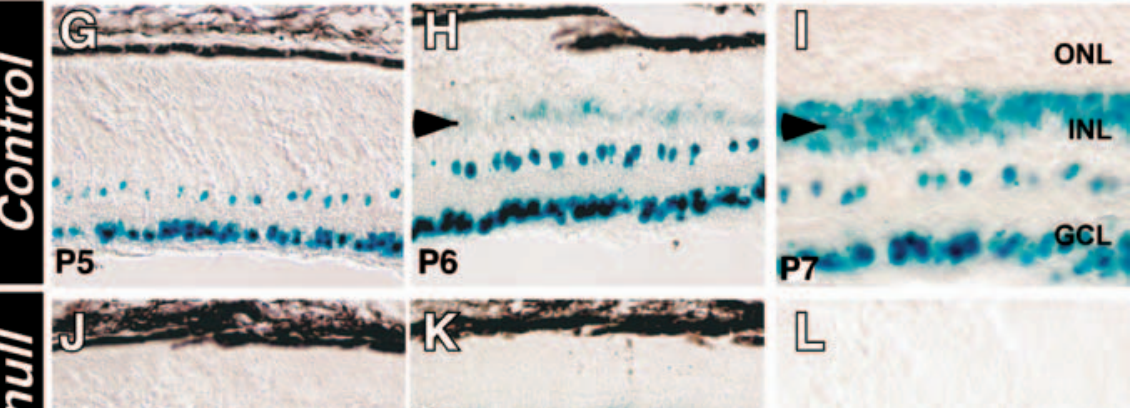

ᄂ
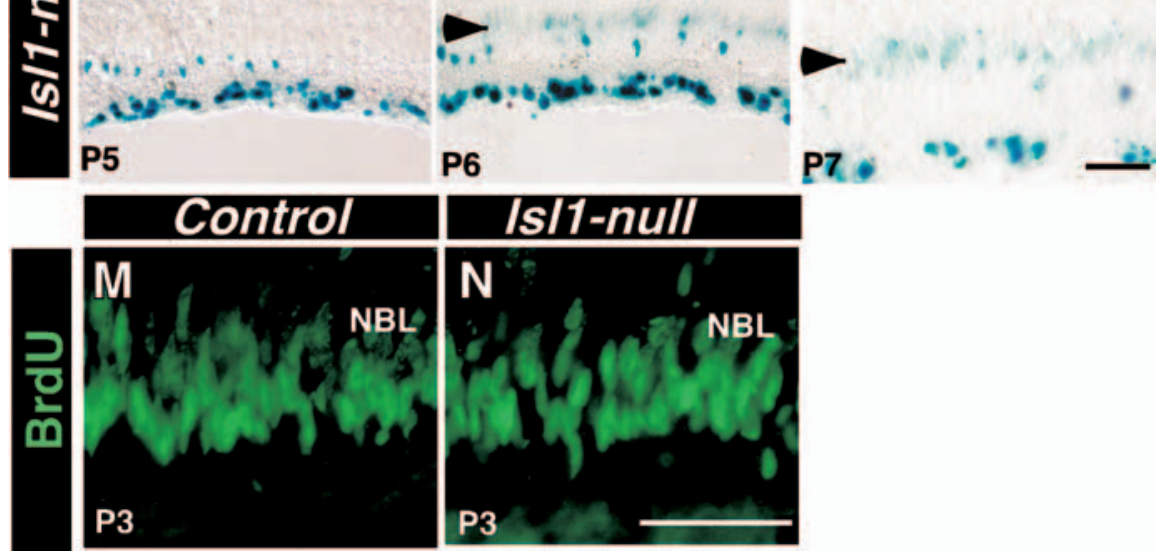

Figure 1. Is 11 -null retinas display a pronounced hypoplasia in the INL and the GCL. $\boldsymbol{A}-\boldsymbol{F}$, Hematoxylin and eosin staining of control $(\boldsymbol{A}-\boldsymbol{C})$ and $/ s / 7$-null $(\boldsymbol{D}-\boldsymbol{F})$ retinas at different ages demonstrate a marked INL hypoplasia at P8 in $/ s / 1$-null retinas $(\boldsymbol{E})$ compared with control $(\boldsymbol{B})$, whereas the $0 \mathrm{NL}$ thickness is normal. This hypoplasia is maintained in the mature retinas of $/ \mathrm{s} / 1$-null animals $(\boldsymbol{F})$ compared with controls $(\boldsymbol{C})$. Although ganglion cell hypoplasia is evident in $/ s / 1$-null retinas at $P 3$ (compare $\boldsymbol{D}, \boldsymbol{A}$ ), the neuroblast layer at this stage is only mildly affected. X-gal histochemistry shows that at $\mathrm{P} 6$, bipolar cells activate the $/ s / 7$ promoter similarly in both $/ s / 1$-null ( $\boldsymbol{K}$, black arrowhead) and control $(\boldsymbol{H}$, black arrowhead) retinas. At P7, Is/1-null retinas exhibit a marked divergence in reporter-positive cells within the bipolar cell layer ( $\boldsymbol{L}$, black arrowhead) compared with control $(\boldsymbol{I}$, black arrowhead). $\boldsymbol{M}, \boldsymbol{N}$, Anti-BrdU immunolabeling reveals no significant difference in control retinas $(\boldsymbol{M})$ compared with $/ s / 1$-null retinas $(\boldsymbol{N})$ in the number of BrdU-incorporating cells after a $30 \mathrm{~min}$ BrdU pulse at P3 $(n=3)$. NBL, Neuroblast layer. Scale bars, $50 \mu \mathrm{m}$.

amacrine cells as in control retina, except for what appeared to be a small population of mispositioned Prox1 + bipolar cells in Isl1nulls (Fig. $2 A, B$, side arrowheads). No appreciable reduction in the numbers of these cell types was clear at P6 (Fig. 2A,B) (average number of Prox $1+$ bipolar cells \pm SD: controls: $210 \pm 25$, $n=3$; Isl1-nulls: $190 \pm 16, n=3 ; p=1$, Student's $t$ test). However, at P7 a 54\% decrease in Prox1+ bipolar cells was observed (Fig. 2C,D) (average number of Prox1 + bipolar cells \pm SD: controls: $169 \pm 14, n=3$; Isl1-nulls: $77 \pm 5, n=3$; $p<0.001$, Student's $t$ test). This decrease in bipolar cell marker expression was maintained at P27 in Isl1-null retinas, as indicated by both Proxl and Chx10 immunostaining. We found a $49 \%$ reduction in 

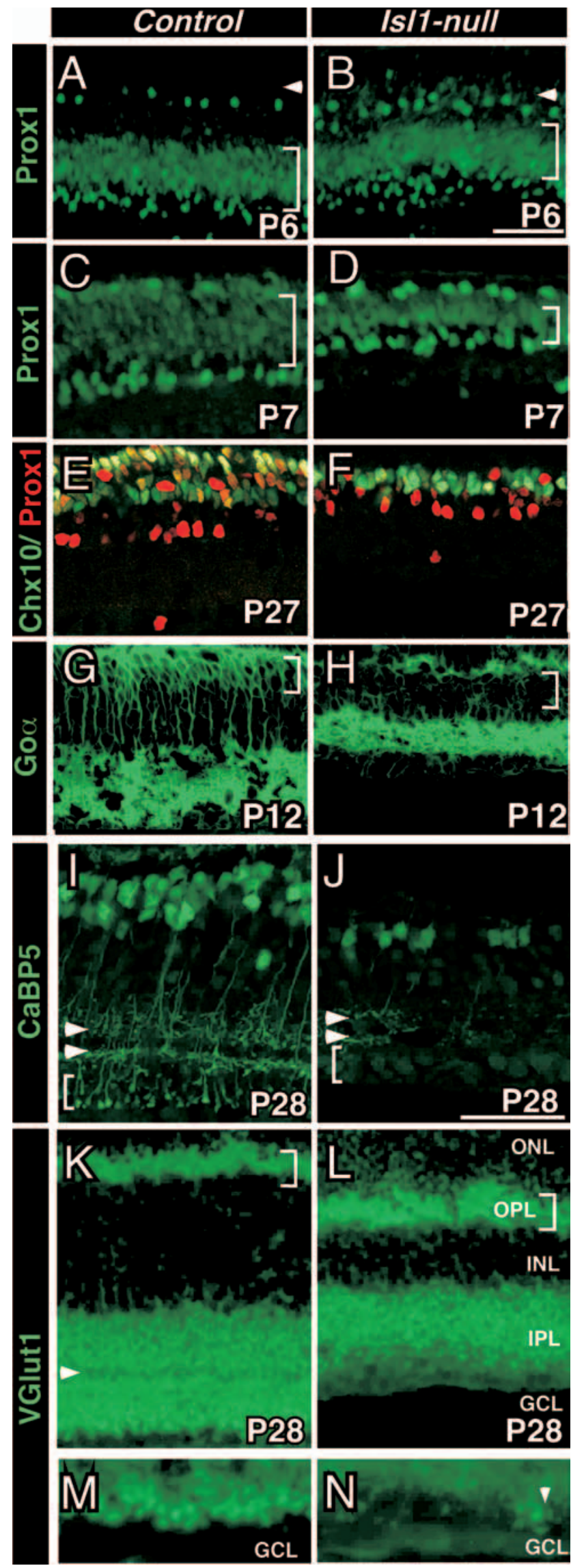

Figure 2. Pan-bipolar and $0 N$-bipolar cell defects in $/ s / 1$-null retinas. $A-D$, The emergence of the bipolar cell marker, anti-Prox1, is not significantly different between control and $/ s / 1$-null retinas at P6 ( $\boldsymbol{A}, \boldsymbol{B}$, brackets), whereas by $\mathrm{P} 8$, anti-Prox 1 immunohistochemistry reveals a sig-
Chx10+ cells in adult Isl1-null retinas compared with those of control littermates (Fig. 2E,F) (average number of Chx10+ cells \pm SD: controls: $93 \pm 9, n=3$; Isl1-nulls: $47 \pm 10 ; p<0.01$, Student's $t$ test). Furthermore, a proportion of the Chx10+ cells in the Isl1-null retina colocalized with residual Isl1+ cells (supplemental Fig. 5, available at www.jneurosci.org as supplemental material), suggesting that the degree of Isl1 deletion from Six3-cre might underestimate the effect of Isl1 on the expression of bipolar cell markers.

We next analyzed the expression of several subpopulations of bipolar cells. Based on the strict colocalization of Isl1 with ONbipolar cell markers in the adult mouse retina, we predicted that the development of this subpopulation of bipolar cells would be affected in the Isl1-null retina (Elshatory et al., 2007). ON-bipolar cells express the G-protein subunit Go $\alpha$ (Vardi et al., 1993; Vardi, 1998; Haverkamp et al., 2003a). Immunostaining for Go $\alpha$ showed that the number of Go $\alpha+$ cell bodies was significantly reduced in the Isl1-null retina (Fig. $2 H$ ) by $76 \%$ compared with the control retina (Fig. 2G) (average number of Go $\alpha+$ bipolar cells \pm SD: controls: $123 \pm 13, n=3$; Isl1-nulls: $29 \pm 5, n=3$; $p<0.01$, Student's $t$ test). Coimmunolabeling of Go $\alpha$ and Isl 1 in the Isl1-null retina at P27 revealed colocalization of a fraction of the remaining Go $\alpha+$ cells with residual Isl1-expressing cells (supplemental Fig. 5, available at www.jneurosci.org as supplemental material).

The disruption of bipolar cell expression in Isl1-null retinas was also supported by changes in other bipolar subtype-specific markers. Anti-CABP5 immunolabeling, which labels subsets of ON- and OFF-cone bipolars as well as rod bipolar cells, was significantly reduced by $64 \%$ in the $I s l 1$-null retina (Fig. $2 I, J$ ) (average number of CABP5 + cells \pm SD: controls: $110 \pm 9, n=3$; Isl1-nulls: $39 \pm 9, n=3 ; p<0.001$, Student's $t$ test) (Haverkamp et al., 2003a). CABP5 immunolabeling of these different subtypes can be distinguished based on the tier within the inner plexiform layer (IPL) that the bipolar cells terminate, and in Isl1-nulls, CABP5 + laminas of ON-cone bipolar, OFF-cone bipolar, and rod bipolar cells were all disrupted (Fig. $2 I$,J, arrowheads and brackets). The vesicular transporter vGlut1, which is expressed in bipolar ribbon synapses across different bipolar subtypes, was also significantly reduced in Isl1-null retinas compared with control (Fig. $K, L$ ) (average thickness in micrometers of VGlut1+ IPL staining \pm SD: controls: $70 \pm 11, n=3$; Isl1-nulls: $39 \pm 11$; $p<0.05$, Student's $t$ test) (Mimura et al., 2002; Haverkamp et al., 2003a; Sherry et al., 2003). The higher intensity vGlutl staining in the globular terminals of rod bipolar cells was markedly diminished in Isl1-null retinas compared with controls (Fig. 2M,N), whereas vGlut 1 staining of photoreceptor terminals was not (Fig. $2 K, L$, brackets), reaffirming a disruption in the expression of rod bipolar cells in Isl1-nulls.

nificant reduction in bipolar cells $(\boldsymbol{C}, \boldsymbol{D}$, brackets). $\boldsymbol{E}, \boldsymbol{F}$, In the mature retina, the marked reduction in bipolar cells is confirmed by anti-Chx10 and Prox1 immunohistochemistry. $\boldsymbol{G}, \boldsymbol{H}$, AntiGo $\alpha$ immunostaining in P12 retinas demonstrates that there is marked loss Go $\alpha$-positive bipolar cells (ON-bipolars) in Is/7-null retinas compared with controls. I, J, Anti-CABP5 immunostaining shows disruption of the OFF-cone bipolar (top arrowhead), the ON-cone bipo$\operatorname{lar}$ (bottom arrowhead), and rod bipolar (bracket) laminas in $/ s / 1$-null retinas $(J)$ compared with control $(\boldsymbol{I} ; n=3) . \boldsymbol{K}, \boldsymbol{L}$, Anti-vGlut1 immunostaining reveals intact expression within photoreceptor terminals in the OPL (brackets) but significantly reduced staining of bipolar terminals measured by the reduced thickness of IPL staining in $/ s / 1$-nulls $(\boldsymbol{L})$ compared with controls $(\boldsymbol{K}$; $n=3) . M, N$, Also, vGlut1 + globular staining at the lower extent of the IPL, representing rod bipolar endings, is markedly reduced in $/ s / 1$-nulls $(\boldsymbol{N}$, arrowhead) compared with controls $(\boldsymbol{M})$. Scale bars, $50 \mu \mathrm{m}$. 
The development of rod bipolar cells was also examined using anti-Prkca immunolabeling, which is expressed broadly by rod bipolars but not other subtypes of bipolar cells (Cuenca et al., 1990; Haverkamp and Wassle, 2000; Haverkamp et al., 2003a). Prkca + rod bipolar cells were assessed in the retinas of control and Isl1-null mice at P6. P6 represented the earliest time point Prkca + bipolar cells were detected (data not shown). Because rod bipolar cells comprise a sizeable fraction of the ON-bipolar cell pool, we predicted that a loss of rod bipolar cells accompanies the reduced expression of Go $\alpha$ in the Isl1-null retina. Emerging Prkca + bipolar cells in the control retina always colocalized with Isl1, although not all Isl1 + cells expressed Prkca (Fig. 3A). At P6, Prkca + bipolar cells extended a process in the direction of the GCL in control retinas (Fig. 3A). However, although Prkca + amacrine cells were present in a similar location to those observed in the control retina (Fig. 3B, side arrowhead), Prkca + bipolar cells could not be detected in Isl1-null retinas on P6 (Fig. 3B). By P7, we detected a $91 \%$ reduction in rod bipolar cells of Isl1-null retinas (Fig. $3 E)(p<$ 0.0001 , Student's $t$ test; $n=3$ ).

We tested the possibility that the emergence of Prkca + bipolar cells is delayed in the Isl1-null retina. Analyzing retinas at P12, when rod bipolar cells maturate (Sherry et al., 2003), we found that all Prkca + bipolar cells colocalized with Isl1 in the control retina (Fig. 3C). By P12, Prkca + rod bipolar cells in the control retina have achieved their mature morphology with short apical dendrites contacting the OPL and a long filamentous process ending in spheroid nerve endings within the IPL (Fig. 3C). In the adult Isl1-null retina, the number of Prkca + bipolar cells was $87 \%$ less than in their littermate controls (Fig. 3C-E) $(p<0.001$, Student's $t$ test; $n=3$ ). To determine whether Isl1 has a cell-autonomous role in the development of rod bipolar cells, we exploited the mosaic pattern of Isll deletion using the Six3-cre transgene and analyzed the residual Isl1 + cells situated in an otherwise Isl1-null environment. If the loss of rod bipolar cell expression were purely non-cell autonomous, the remaining Prkca + rod bipolar cells need not appreciably colocalize with the remaining Isl1 + cells. To test this, we sampled a total of 50 Prkca + rod bipolar cells from three Isl1-null retinas and found that 48 of the 50 cells expressed both Prkca and Isl1, whereas only 2 cells expressed Prkca alone (Fig. $3 D, F$ ), confirming the intrinsic requirement for Isl1 in the development of rod bipolar cells. However, because Prkca + bipolar cells had less distinctive bipolar cell morphology, Prkca + /Isl1 - cells that are, in fact, amacrine cells may be mistaken for bipolar cells. To examine whether
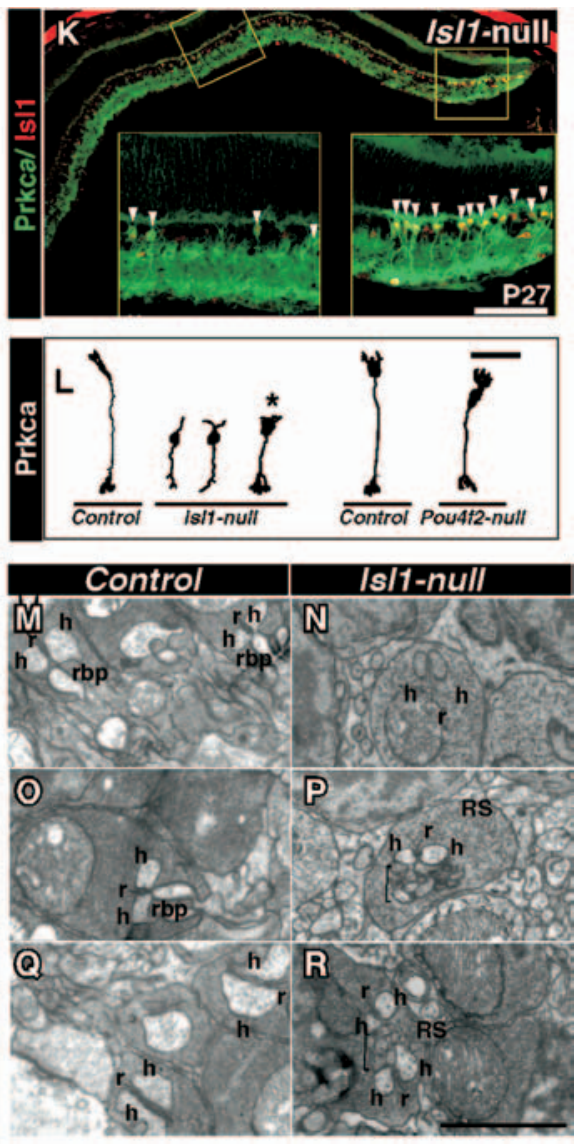

Figure 3. Is 11 is required for rod bipolar development and synapse formation. $\boldsymbol{A}, \boldsymbol{B}$, Anti-Prkca and anti-Isl1 double immunolabeling demonstrate that emerging Prkca + rod bipolar cells are uniformly Is $11+$ at P6 in controls $(\boldsymbol{A}$, arrowheads) and that the emergence of Prkca + rod bipolar cells in /s/1-null retinas compared with controls is reduced at P6 ( $A$, arrowheads; side arrows in $\boldsymbol{A}$ and $\boldsymbol{B}$ indicate Prkca + amacrine cells). $\boldsymbol{C}, \boldsymbol{D}, \mathrm{At}$ P12, more mature Prkca + rod bipolar cells are also $\mathrm{ls} 1 \mathbf{1}+(\boldsymbol{C})$, and stray Prkca + cells). $\boldsymbol{E}$, Quantitation of Prkca + rod bipolars demonstrate a 91\% reduction in /s/1-nulls compared with controls at P7 and an 87\% Prkca + cells in /s/1-null retinas colocalize with the pan-amacrine cell marker Pax6 ( $\boldsymbol{H}$, arrowheads), cells also found in controls ( $\boldsymbol{G}$ comonstrate control-like morphology only when a clustering of Is $11+$ cells is observed in the /s/1-null retina at the (arrowheads in insets). L, Two-dimensional renditions of Prkca + rodbipolars in control, $/ s / 1$-null, and Poutf2-null Pou4f2-nulls (asterisk indicates rod bipolar at retinal margin). $\boldsymbol{M}-\boldsymbol{R}$, Representative electron micrographs of rod synapses in control $(\boldsymbol{M}, \mathbf{0}, \mathbf{Q})$ and $/$ s/1-null $(\boldsymbol{N}, \boldsymbol{P}, \boldsymbol{R})$ retinas demonstrate typical triad synapses in controls $(\boldsymbol{M}, \mathbf{0})$ composed of two horizontal cell processes $(\mathrm{h})$, a ribbon $(\mathrm{r})$, and an invaginating rod bipolar process (rbp). Diads $(\mathbf{Q})$ represented a smaller proportion of juxtaposed ribbon structures $(\boldsymbol{R})$ and multiloculated endings with a soap-bubble appearance $(\boldsymbol{P})$ unique to $/ s / 1$-null retinas. Scale bars: $\boldsymbol{A}-\boldsymbol{J}$, insets in $\boldsymbol{K}, 50 \mu \mathrm{m} ; \boldsymbol{L}, 20 \mu \mathrm{m} ; \boldsymbol{M}-\boldsymbol{R}, 2 \mu \mathrm{m}$. Error bars indicate averages plus SD. ${ }^{* * *} p<0.001 ;{ }^{* * *} p<0.0001$.

Prkca + cells in the Isl1-null retina overlap with the panamacrine marker Pax6, coimmunolabeling using anti-Prkca and anti-Pax6 was performed. Indeed, Prkca + cells positioned close to the IPL colocalized with Pax6 + cells in both controls and Isl1-null retinas and are thus amacrine cells (Fig. $3 G, H)$.

The bHLH transcription factor Bhlhb4 is required for the normal development of rod bipolar cells. In its absence, Prkca + rod bipolar cells emerge but degenerate shortly thereafter (Bramblett et al., 2004). We sought to determine the genetic relationship of Isl1 and Bhlhb4 by assessing the expression of Bhlhb4 mRNA in the retinas of Isl1-null mice and control littermates. Indeed, at P6, 
Table 1. Quantification of rod synaptic structures

\begin{tabular}{lcccc}
\hline & Number of triads & Number of diads & Multiple ribbons & $\begin{array}{l}\text { Multiloculated } \\
\text { endings }\end{array}$ \\
\hline Control & $125(53.9 \%)$ & $105(45.3 \%)$ & $2(0.9 \%)$ & $0(0 \%)$ \\
Is/1-null & $15(7.1 \%)$ & $105(49.5 \%)$ & $22(10.4 \%)$ & $70(33.0 \%)$ \\
\hline
\end{tabular}

Retinas were derived from three animals in each genotype group. A total of 100 micrographs of control retinas and 100 micrographs of $/ s / 1$-null retinas taken at $7000 \times$ were counted. Percentages of the total number of terminals with ribbons are in parentheses.

the expression of Bhlhb4 was markedly reduced in the Isl1-null retina compared with control (Fig. I, J, side arrowhead), suggesting that Isl1 could act upstream of Bhlhb4 during the development of rod bipolar cells.

Despite expressing Isl1 and Prkca, the majority of rod bipolar cells in the Isl1-null retina failed to demonstrate "wild type" morphology (Fig. 3D, arrowheads, $K$, left inset). Indeed, significant differences were observed in dendritic and terminal arborizations of the rod bipolar cells remaining in the Isl1-null retina compared with control and Pou4f2-null retinas (Fig. $2 L$ and supplemental Fig. 7, available at www.jneurosci.org as supplemental material). We noted that RGC loss was similarly severe in Pou4f2-null and Isl1-null retinas (supplemental Fig. 2, available at www.jneurosci. org as supplemental material) (Gan et al., 1999). Rod bipolar dendritic and terminal arborizations occupied smaller areas in Isl1-null retinas than in controls, but this did not appear to result from non-cell-autonomous effects of RGC loss alone because rod bipolar dendritic and terminal arborizations in Pou4f2-null retinas did not differ significantly from controls (Fig. $2 L$ and supplemental Fig. 7, available at www.jneurosci.org as supplemental material). Arborizations of certain rod bipolar cells at the peripheral margin in Isl1-null retinas did not differ significantly from those of either Pou4f2-null or control retinas and seemed to be associated with a clustering of Isl1+ cells in this area (Fig. $2 \mathrm{~K}$, right inset, $L$, and supplemental Fig. 7, available at www.jneurosci. org as supplemental material). Thus, although most Prkca + bipolar cells in the Isl1-null retina express Isl1, Isl1 is generally insufficient to form rod bipolars with wild-type-like dendritic and terminal arborizations, revealing a non-cell-autonomous role for Isl1 in rod bipolar development that does not arise solely from the accompanying RGC loss.

Rod terminals were investigated at the ultrastructural level to assess the integrity of a predominant subset of photoreceptor-tobipolar cell synapses in the Isl1-null retina. Unlike the rod synapse, cone synapses are too structurally heterogeneous to quantify by subtype in control versus conditional knock-out at the level of electron microscopy. We focused our analysis instead on rod bipolar cells, which are readily identified, easily quantified, and represent a large fraction of the bipolar cell pool affected in Isl1-null retinas. Although electron micrographs of rod synapses in control retinas revealed a predominance of triad synapses (53\%) (Table 1, Fig. $3 \mathrm{M}, \mathrm{O}$ ), consisting of two horizontal cell processes with central, invaginating rod bipolar processes, only $7.1 \%$ of synapses in Isl1-null retinas were triads (Table 1 ). Instead, the most frequently encountered synaptic structure in Isl1null retinas was the diad, which lacks invaginating rod bipolar processes (Table 1, Fig. $3 N$ ). Furthermore, rod synapses with rare or abnormal morphologies markedly increased from $0.9 \%$ in controls to $43.4 \%$ in Isl1-nulls and included synapses with multiple, closely juxtaposed ribbons (Table 1, Fig. 3R) and ribbons with electron-dense, "multiloculated" endings (Table 1, Fig. $3 P, R)$. The latter structures, observed only in Isl1-null retinas, were so named because they apposed the horizontal cell processes and had a soap-bubble appearance.
Because of the concurrent loss of multiple cell types in the Isl1-null retina, it is unclear whether defects in late-born cell types, such as bipolar cells, result from defects in the development of earlier-born types, such as RGCs. In fact, the depletion of RGCs or RGC-dependent factors, such as Shh (sonic hedgehog) can lead to retinal hypoplasia (Mu et al., 2005; Wang et al., 2005). So to test whether a comparable loss of RGCs as in Isl1-null retinas is sufficient to produce the observed bipolar phenotype, we assessed the expression of bipolar subtype-specific markers in Pou4f2-null mice (Gan et al., 1999). Despite 70-80\% RGC depletion in these mice (Gan et al., 1999; Lin et al., 2004), we detected no significant differences in the numbers of ON- and OFFbipolar subtypes by immunolabeling experiments against various subtype-specific bipolar cell markers (supplemental Fig. 4, available at www.jneurosci.org as supplemental material). Thus, effects on bipolar cell development after Isl1 deletion are likely to arise independent of the preceding RGC loss.

Given the restricted Isl1 expression to ON-type bipolar cells in the mature retina and barring the possibility that Isl1 expression earlier in the ontogeny of bipolar cells is broader, we postulated that the function of Isl1 in bipolar cell development is restricted to ON-type cells (Elshatory et al., 2007). However, disruptions in the expression of CABP5 within both ON- and OFF-bipolar laminas suggest otherwise (Fig. $2 I, J$ ). We explored the extent to which the requirement for Isl1 in bipolar cell differentiation is restricted to ON-bipolars by assessing the acquisition of additional OFF-type bipolar markers in the Isl1-null retina compared with littermate controls. We used markers specific for different or overlapping subpopulations of OFF-bipolar cells, such as Recoverin, Bhlhb5, and Vsx1 (Milam et al., 1993; Chow et al., 2001; Feng et al., 2006). Vsx1 expression within OFF-bipolar cells encompasses those of Bhlhb5 and Recoverin, which nearly completely overlap in bipolar cells (Feng et al., 2006). Immunolabeling for Recoverin revealed a 95\% reduction in Recoverin + OFFbipolar cells in the Isl1-null retina compared with control littermates (Fig. 4A,B) (average number of Recoverin + bipolar cells \pm SD: controls: $15 \pm 3, n=4$; Isl1-nulls: $1 \pm 1, n=4$; $p<$ 0.01 , Student's $t$ test). However, Recoverin + photoreceptors were still observed in the outer nuclear layer (ONL) of Isl1-null retinas (Fig. $4 A, B$ ). Immunolabeling for Bhlhb5+ bipolar cells revealed only a $45 \%$ reduction in Isl1-null retinas compared with controls (Fig. 4C,D) (average number of Bhlhb5 + bipolar cells \pm SD: controls: $23 \pm 2, n=4$; Isl1-nulls: $12 \pm 2, n=4$; $p<0.01$, Student's $t$ test) and suggests that the class of Recoverin and Bhlhb5 double-positive bipolar cells partially remains but does not express Recoverin in the Isl1-null retina.

The absence of Recoverin + bipolar cells has recently been observed in retinas where $V s \times 1$ is disrupted (Chow et al., 2004; Ohtoshi et al., 2004). To determine whether the expression of Vsx1 was diminished after Isl1 disruption, we compared the extent of immunolabeling for Vsx1 in Isl1-null retinas with those of their control littermates at P7 and P27. At P7, 85\% fewer Vsx1+ cells were encountered in the INL of Isl1-null retinas compared with their control littermates (Fig. $4 E, F$ ) (average number of Vsx $1+$ cells \pm SD: controls: $167 \pm 13, n=3$; Isl1-nulls: $25 \pm 5$, $n=3 ; p<0.0001$, Student's $t$ test). Similarly, at P27, 78\% fewer Vsx1 + cells were present in the INL of Isl1-nulls compared with controls (Fig. 4G,H) (average number of Vsx1+ cells \pm SD: controls: $52 \pm 6, n=4$; Isl1-nulls: $12 \pm 4, n=4 ; p<0.01$, Student's 


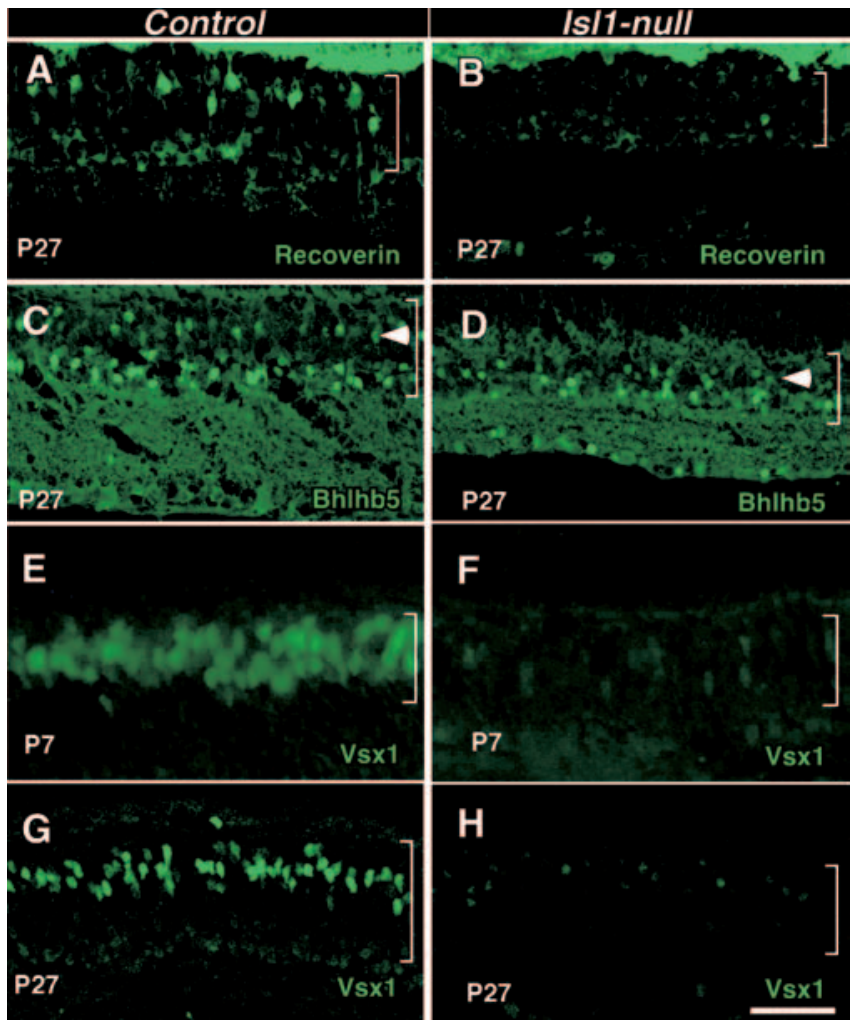

Figure 4. OFF-bipolar cells fail to differentiate appropriately in IsI1-null retinas. Confocal micrographs of cone bipolar marker expression in developing and mature retina from IsI1-null and control littermates are shown. $\boldsymbol{A}, \boldsymbol{B}$, Recoverin expression in OFF-cone bipolars is nearly absent in Is|1-null retinas $(\boldsymbol{B})$ compared with control littermates $(\boldsymbol{A})$, showing a 95\% reduction in Is|1-nulls after quantitation $(n=4) . C, D, B h l h b 5$, a marker of developing and mature OFF-cone bipolars, is reduced $45 \%$ in IsI1-null retinas ( $\boldsymbol{D}$, arrowhead) compared with control ( $\boldsymbol{C}$ arrowhead; $n=4) . E, F, V s \times 1$, an additional marker of developing and mature OFF-cone bipolars, is reduced by $85 \%$ in Is 11 -null retinas at $\mathrm{P7}(\boldsymbol{F})$ compared with controls $(\boldsymbol{E} ; n=3) . \boldsymbol{G}, \boldsymbol{H}$ Vsx1 immunolabeling is similarly reduced in the mature Is11-null retina $(\boldsymbol{H})$ compared with control (G), showing a $78 \%$ reduction $(n=4)$. Brackets demarcate the INL. Scale bar, $50 \mu \mathrm{m}$.

$t$ test). Thus, Vsx1 immunolabeling revealed that $I s l 1$-null retinas have an early and persistent loss of Vsx1 protein expression.

\section{Dynamic expression of multiple LIM-homeobox genes in developing bipolar cells}

Whereas the expression of Isl1 within bipolar interneurons in the mature retina is restricted to the $\mathrm{ON}$ type, its expression earlier in the ontogeny of bipolar cells may exceed that of the ON pool of cells. To determine whether Isl 1 expression in developing bipolar cells is less subtype specific than its expression in the mature retina, coimmunolabeling of Isl1 and an OFF-bipolar marker, Bhlhb5, was assessed at P6 and P19. At P19, although no colocalization was observed for Isl1 and Bhlhb5 (Fig. 5B), a large proportion of Isl1 + bipolar cells colocalized with Bhlhb5 in the P6 retina (Fig. 5A, arrowheads). Thus, the subtype specificity of either Isl1 and/or Bhlhb5 expression differs at these different developmental stages, suggesting that Isl1 could function cellautonomously to affect OFF-bipolar cell differentiation.

Despite the expression of Isl1 in adult retinal bipolar cells being subtype specific, the functional consequence of Isl1 loss of function and its developmental expression within bipolar cells indicated otherwise. Because Islet-class LIM-homeodomain proteins are known to participate with Lhx-class LIMhomeodomain proteins combinatorially to differentially instruct the development of distinct neuronal cell types (Thaler et al., 2002), we sought to characterize the mRNA expression of several LIM-homeobox genes throughout the peak generation and differentiation of bipolar cells in the mouse retina and thereby determine whether bipolar cell development depends on the function of multiple, coordinately acting LIM-homeobox genes in addition to Isll. Indeed, in situ hybridization experiments showed that developing bipolar cells expressed Isl1, Lhx3, Lhx4, and $L d b 1$ either individually or in combination (Fig. 5C, E, F, H). Isl1 expression from P0 to P5 was restricted to the GCL and the inner leaflet of the INL (Fig. 5C). Isl1 expression within developing bipolar cells began at P5 and expanded in the ensuing days (Fig. 5C). Isl2 expression was not detected outside of the GCL (Fig. 5D). Expression of the $L h \times 3$ and $L h \times 4$ mRNAs corresponded spatially and temporally to bipolar cells (Fig. $5 E, F$ ), whereas that of $L h x 7$ did not (Fig. 5G). $L d b 1$ expression encompassed the GCL and the INL (Fig. $5 H$ ). Expression of $L d b 1 \mathrm{mRNA}$ within the INL included regions occupied by both developing amacrine cells (the inner portion of the INL) and developing bipolar cells (the outer portion of the INL).

To confirm the colocalization of Lhx3 and Lhx4 with Isl1, we examined coimmunolabeling of Isl1 with Lhx3 or Lhx4 in retinas at P7, a time when expression levels of Isl1, $L h \times 3$, and $L h \times 4$ appeared to peak by in situ hybridization (Fig. $5 C, E, F$ ). Indeed, partial colocalization of Isl1 with Lhx3 and Lhx4 was observed at P7 (Fig. 5I, $I^{\prime}, J, J^{\prime}$ ). Furthermore, although the expression of Lhx3 was essentially abolished at P7 in the Isl1-null retina (Fig. $5 K^{\prime}$ ), Lhx4 immunostaining was relatively unaltered (Fig. $5 L^{\prime}$ ), arguing for potentially nonredundant roles for Lhx 3 and Lhx 4 in retinal neurogenesis, as opposed to redundancy encountered in other CNS regions for these two factors (Sharma et al., 1998).

Isl1 regulates the differentiation of cholinergic amacrine cells The expression of Isl1 by cholinergic amacrine cells in the adult mouse retina and the emergence of Isll expression within differentiating amacrine cells embryonically suggest that Isll may be required for the establishment of cholinergic amacrines (GalliResta et al., 1997; Elshatory et al., 2007). To gauge the emergence of cholinergic amacrine cells in retinas devoid of Isl1, coimmunolabeling for Isl1 and ChAT was analyzed in the $\mathrm{P} 6$ retina. ChAT immunolabeling identifies amacrine cells in the GCL and in the inner portion of the INL (Kondo et al., 1985). In control retinas at P6, ChAT + amacrine cells always colocalized with Isl1 (Fig. 6A). Furthermore, ChAT + processes coalesced to form a band of staining within the IPL by P6 (Fig. $6 \mathrm{~A}$, side arrowhead). In Isl1null retinas, however, the presence of distinguishable ChAT + amacrines was not apparent nor was the presence of ChAT+ amacrine cell processes within the IPL (Fig. 6B).

To determine whether cholinergic amacrine expression is lost or only delayed in its appearance, ChAT and Isll coimmunolabeling was examined in the P27 retina. Whereas cholinergic amacrines in Isl1-null retinas were sparse (Fig. 6E), the retinas of control littermates displayed many ChAT + amacrine cells along the two ON and OFF sublaminas (Fig. 6D). Indeed, the number of cholinergic amacrines was $93 \%$ less in adult Isl1-null retinas compared with control littermates (Fig. 6C) (average number of ChAT + amacrine cells \pm SD: controls: $34 \pm 6, n=3$; Isl1-nulls: $2 \pm 2, n=3 ; p<0.001$, Student's $t$ test). Plotting the intensity of anti-ChAT staining across the retina reaffirmed the loss of ChAT + sublaminas in Isl1-nulls (Fig. 6 F).

To determine whether Isl1 has a cell-autonomous role in the development of cholinergic amacrine cells, we again exploited the mosaic pattern of Isl 1 deletion to test what fraction of a sample of 

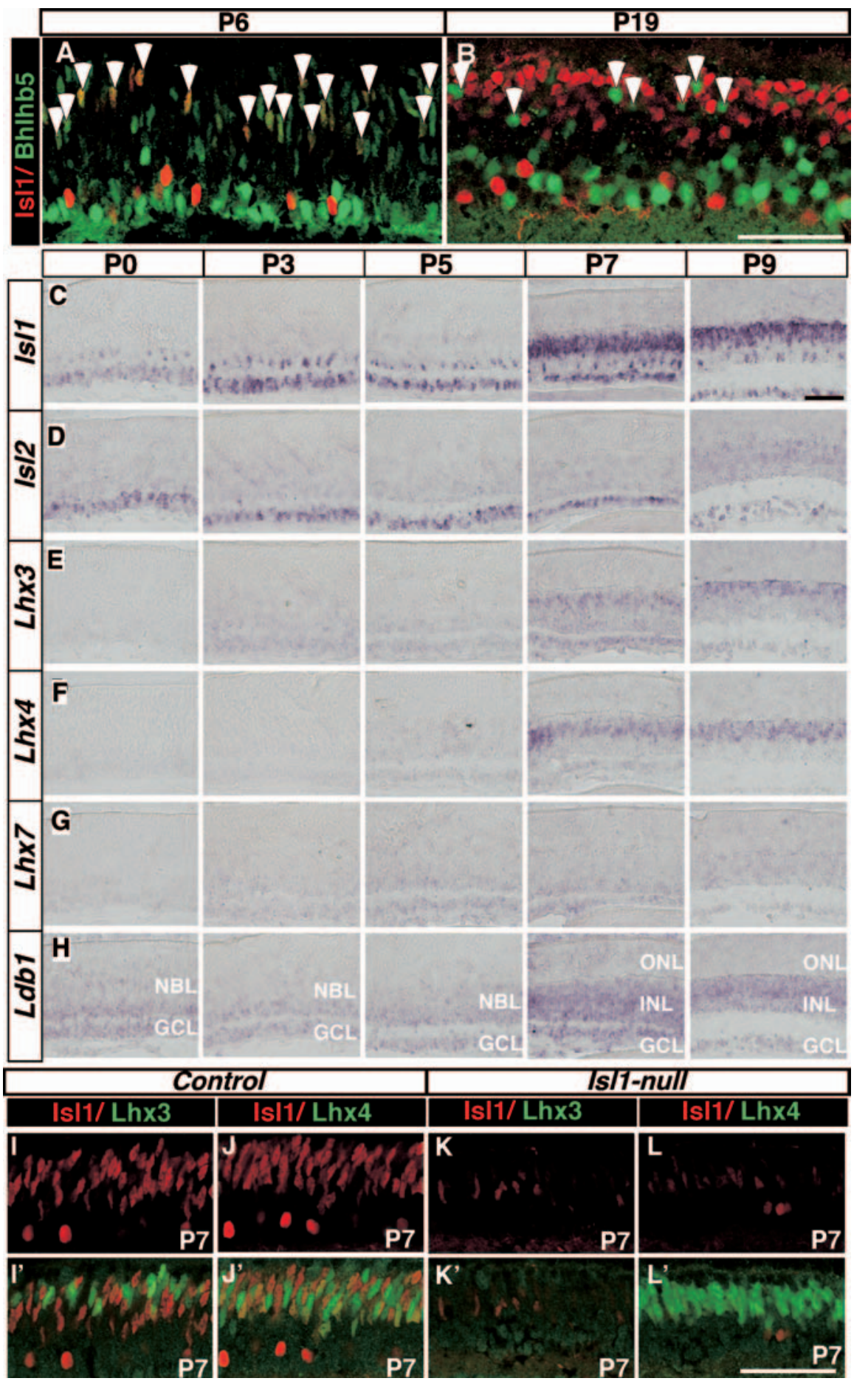

Figure 5. Dynamic expression of IsI1, Lhx3 and Lhx4 reveals a potential LIM code during bipolar cell development. $\boldsymbol{A}, \boldsymbol{B}$ Confocal micrographs of I $\mathrm{I} 11$ colocalization with Bhlhb5 within the INL at P6 (A) and P19 (B) demonstrates transient colocalization of Isl1 with the OFF-bipolar marker Bhlhb5 at P6 ( $\boldsymbol{A}$; arrowheads point to colocalizing cells) but not P19 ( $\boldsymbol{B}$; arrowheads point to cells singly positive for Bhlhb5). Light micrographs of in situ hybridization experiments depict the mRNA expression profiles of several Lhx-class and IsI-class transcription factors during the first and second postnatal weeks of retinal development. $C$, Is 11 expression from PO to P5 is restricted to the $G C L$ and the inner leaflet of the INL. D, Beginning at P5, expression within developing bipolar cells commences and expands in the ensuing days. $\boldsymbol{D},|\mathrm{Is}| 2$ expression is confined to the GCL. $\boldsymbol{E}-\boldsymbol{G}$, Expression of the Lhx3 $(\boldsymbol{E})$ and $\operatorname{Lhx} 4(\boldsymbol{F})$ mRNAs corresponds spatially and temporally to Isl1 expression within bipolar cells (Fig. 8), whereas that of Lhx7 (G) does not. Lhx3, Lhx4, and Isl1 peak at P7. $\boldsymbol{H}$, Ldb1, encoding the LIM-domain binding protein 1 , is expressed in the GCL and the INL. $I-L^{\prime}$, Confocal micrographs of coimmunolabeling for Isl1 and $L h x 3\left(I, I^{\prime}, K, K^{\prime}\right)$ or Lhx4 $\left(\boldsymbol{J}, J^{\prime}, \boldsymbol{L}, \boldsymbol{L}^{\prime}\right)$ at P7 show partial colocalization of Isl1 with Lhx3 and Lhx4. Expression of Lhx4 is broader in the control retina $\left(J^{\prime}\right)$ and is relatively spared in the IsI1-null retina $\left(L^{\prime}\right)$. Expression of $L$ hx $3\left(I^{\prime}\right)$ is more restricted in the control than Lhx4 $\left(\boldsymbol{J}^{\prime}\right)$ and is abolished in the Isl1-null retina $\left(\boldsymbol{K}^{\prime}\right)$. Scale bars, $50 \mu \mathrm{m}$.
35 cholinergic amacrine cells in the Isl1null retina colocalizes with Isl1 (as in Fig. $6 E)$. Indeed, all 35 cholinergic amacrine cells sampled colocalized with Isl1, suggesting that Isl1 expression in an otherwise Isl1-null environment is sufficient to permit cholinergic amacrine cell differentiation.

The loss of additional markers of cholinergic amacrines cells further supported the claim that this cell type is disrupted in the Isl1-null retina. Cholinergic amacrine cells comprise a fraction of the Calretinin + amacrine cell pool (Gabriel and Witkovsky, 1998; Yoshida et al., 2001). Calretinin immunolabeling was therefore assessed to gauge the degree to which the differentiation of cholinergic amacrine cells is affected in the Isl1-null retina. The processes of Calretinin + amacrine cells coalesce to form three distinct laminas within the IPL. The two flanking laminas represent processes from cholinergic amacrine cells, whereas the middle lamina corresponds to the processes of Calretinin $+/$ ChAT - amacrine cells. Calretinin and ChAT double immunolabeling revealed that the Isl 1 -null retina possessed a single Calretinin + lamina (Fig. $6 \mathrm{H}$, arrowhead), as opposed to the three laminas expressed in the retina of control littermates (Fig. 6G, arrowheads). The intensity profile of anti-Calretinin staining across the retina supported this claim (Fig. 6I). Cholinergic amacrines also comprise a fraction of the GAD65 + pool of GABAergic amacrine cells, and although antiGAD65 immunolabeling revealed multilaminar IPL staining in controls (Fig. $6 J$ ), only two laminas were present in Isl1nulls (Fig. $6 K, L$ ). In contrast, $\mathrm{TH}+$ dopaminergic amacrines, a pool distinct from cholinergic amacrines, were preserved in Isl 1 -nulls (Fig. 6M-O). In addition, the number of cells labeled with the panamacrine marker Pax6 was not significantly reduced in Isl1-nulls compared with controls (Fig. 6P,Q) (average number of Pax6+ amacrine cells \pm SD: controls: $168 \pm 20, n=4$; Isl1-nulls: $146 \pm 29$, $n=4 ; p=0.27$, Student's $t$ test). Therefore, multiple markers of cholinergic amacrines (ChAT, Calretinin, GAD65) were disrupted in Isl1-nulls to support the hypothesis that this subtype of amacrine cells is preferentially lost after Isll disruption.

\section{Isl1-null mice display losses of retinal and visual functions}

To determine whether the disruption of Isll in the retina leads to observable physiological defects, we compared darkadapted ERGs recorded from Isl1-null 
mice to those from control littermates. Control mice yielded the classic ERG waveform (Fig. 7A, top trace) consisting of an initial corneal-negative a-wave (reflecting phototransduction processes) followed by a corneal-positive b-wave (reflecting postsynaptic processes). The ERG of dark-adapted Isl1-null mice, however, contained no b-wave, displaying only an unmasked a-wave or, more specifically, the P-III component of the ERG (Fig. 7A, bottom trace). Furthermore, the b-wave from control mice exhibited a normal intensity-response relationship, whereas no b-wave was detected in Isll-null mice over the entire range of intensities tested, indicating a disruption in postphotoreceptor responses (Fig. 7B). Isl1 deletion therefore leads to physiological dysfunction consistent with a cell type-dependent retinal defect.

To assess visual function, we measured acuity and contrast sensitivity of Isl1-null and control littermates by analyzing optomotor responses to rotating sinusoidal patterns. Isl1-null mice exhibited a $46 \%$ loss of visual acuity relative to controls (Fig. $7 C)(p<0.01$, Student's $t$ test; $n=$ $3)$. Contrast sensitivity was also significantly lower in Isl1-null mice (Fig. 7C) $(p<0.01$, Student's $t$ test; $n=3)$. In fact, contrast sensitivity of the mutants was equal to $\sim 1$ (Fig. 7C), which corresponds to $100 \%$ pattern contrast and is indicative of very poor visual function. Together, losses in acuity and contrast sensitivity indicate severely reduced visual function in Isl1-null mice.

\section{Discussion}

A potential LIM code governs bipolar cell development

Different motor neuron phenotypes appear to emerge as a result of coordinately acting LIM-homeodomain proteins, such as Isl1, Isl2, Lhx1, Lhx3, and Lhx4 (Tsuchida et al., 1994; Pfaff et al., 1996; Thaler et al., 2002). Strikingly, the expression profiles of Isl1, Lhx3, and Lhx4 in the developing retina place these three LIMhomeobox genes within the spatiotemporal interval corresponding to bipolar cell differentiation, suggesting that their coordinated action in motor neuron development may have been co-opted for bipolar interneuron diversification. The Lhx4 mRNA expression pattern in the developing mouse retina is consistent with a previous report (Blackshaw et al., 2004). Furthermore, Isl1 was broadly required for the differentiation of bipolar cells, which can be likened to its broad role in motor neuron development. Isl1 partially colocalized with the Lhx-class proteins 3 and 4 in the P7 retina, a time when a disruption in bipolar cell marker expres-

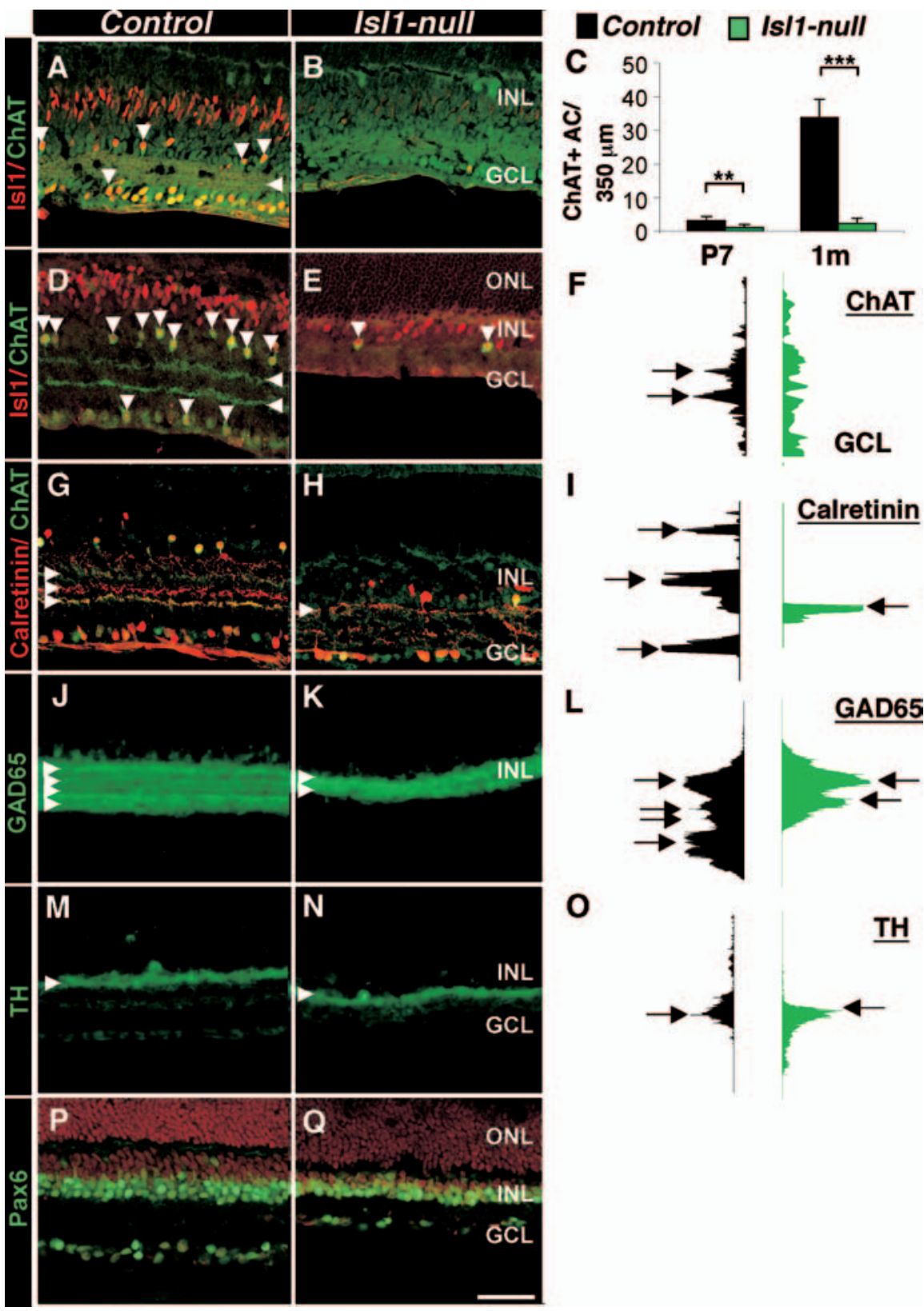

Figure 6. Is|1 is required for cholinergic amacrine development. Confocal micrographs of cholinergic marker expression in developing and mature retina from $/$ s/1-null and control littermates are shown. $\boldsymbol{A}, \boldsymbol{B}$, Anti-ChAT immunofluorescence, a marker of cholinergic or starburst amacrines, is absent at $\mathrm{P} 6$ in /s/1-null retinas $(\boldsymbol{B})$ compared with control $(\boldsymbol{A})$. $\boldsymbol{D}$, Quantitation at $\mathrm{P7}$ reveals a significant decrease in ChaT + amacrine cells, with the mature $/$ s/1-null retina having a $93 \%$ reduction in ChAT + amacrines. $\boldsymbol{E}$, In the adult/s/1-null retina, sparsely distributed ChAT + amacrine cells are always Is $11+$ (arrowheads; compare with controls in D) Also, ChAT + laminas are not distinct in plots of intensity profiles across the mutant retina $(\boldsymbol{F})$. G, Anti-ChAT and anti-calretinin coimmunolabeling depicts three laminas within the IPL of control retinas (side arrowheads): a central Calretinin +/ChAT lamina flanked by two ChAT and Calretinin double-positive laminas. $\boldsymbol{H}$, A single Calretinin +/ChAT- lamina persists in the /s/1-null retina (side arrowhead), depicted by plotting the intensity profile across the retinal layers in $I$. Anti-GAD65 immunolabeling identifies GABAergic amacrines, which include the population of starburst amacrines. $J$, The four major GAD65 + laminas in the control are reduced to two in the $/ s / 1$-null retina $(\boldsymbol{K})$, as shown in the intensity profile in $\boldsymbol{L} . \boldsymbol{M}, \boldsymbol{N}, \mathrm{TH}+$ amacrines, in contrast, are apparently undisrupted, having a single laminar organization in both control $(\boldsymbol{M})$ and $/$ s/1-nulls $(\boldsymbol{N})$ as depicted in $\mathbf{0}$. $\boldsymbol{P}, \boldsymbol{Q}$, The pan-amacrine marker Pax6 reveals no significant reductions in the numbers of Pax6 + amacrines in $/$ s/1-null retinas compared with controls $(n=4)$. Scale bar, $50 \mu \mathrm{m}$. Error bars indicate averages plus SD. ${ }^{* *} p<0.002 ;{ }^{* *} p<0.001$.

sion was observed in the retinas of Isl1-null mice (Fig. 2, Table 2). Given the dynamic nature of the expression of Isl1 in bipolar cells, it is unclear whether Isl and Lhx colocalization patterns parse the developing bipolar cell pool into different bipolar subtypes. 

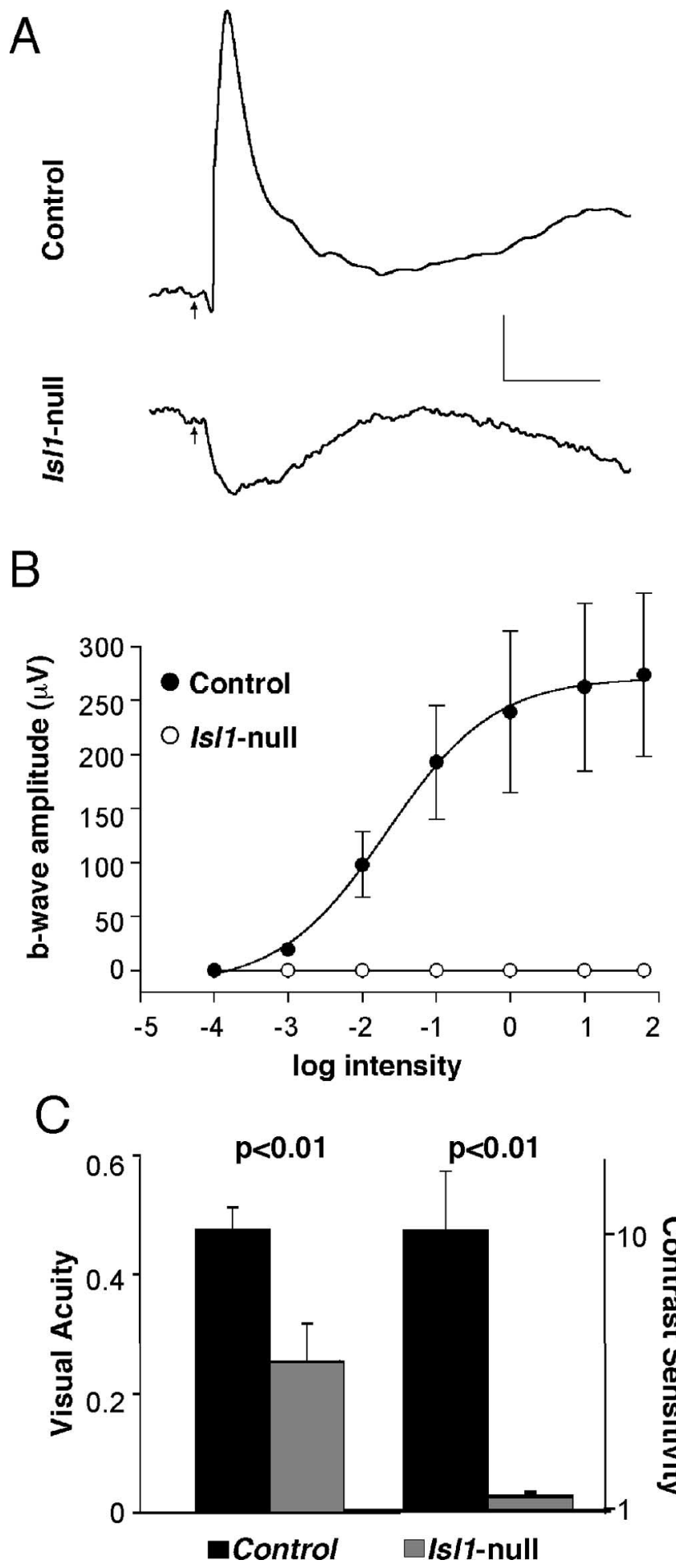

Figure 7. Isl1-null mice exhibit losses in both retinal and visual function. $\boldsymbol{A}$, Average ERG responses recorded from control (top trace; $n=3$ ) and $/$ s/1-null (bottom trace; $n=3$ ) mice. Control mice display the classic ERG waveform (top trace), whereas /s/1-null mice exhibit a complete loss of the b-wave (bottom trace) that unmasks the a-wave/P-III response (bottom trace). Calibration: $50 \mu \mathrm{V}, 200 \mathrm{~ms}$. $\boldsymbol{B}$, Intensity-response functions for the ERG b-wave are normal for the same control mice (filled circles; $n=3$ ) but are not measurable for $/$ s $/ 1$-null mice (open circles; $n=3$ ) because no b-wave response was detected in /s/1-null mice over the entire range of intensities tested. $C$, Visual acuity and contrast sensitivity of control (black bars; $n=3$ ) and /s/1-null (light bar; $n=3$ ) mice as measured by optomotor behavior. Is/1-null mice perform significantly poorer than control mice in tests of both visual acuity and contrast sensitivity. Error bars indicate averages plus SD.
Isl1 regulates $\mathrm{ON}$ - and OFF-bipolar differentiation programs Bhlhb4 and Vsx1, ON- and OFF-bipolar factors, respectively, had markedly altered expression in Isl1-null retinas (Figs. 3, 4). Although there is a trend for decreased expression of the panbipolar marker Prox1 at P6, the number of Prox 1+ bipolar cells was not significantly different at this time point (Fig. 2). However, at P7, a significant reduction in the number of bipolar cells occurred in the absence of elevated markers of cell death (Fig. 2; supplemental Fig. 6, available at www.jneurosci.org as supplemental material; and data not shown). Comparable numbers of developing bipolars initially (Fig. 2) together with equivalent numbers of BrdU-incorporating cells at $\mathrm{P} 3$ when bipolar genesis normally peaks (Fig. 1) suggest that bipolar specification is largely unaffected in the Isl1-null retina. Although we attempted to assess the generation of Isl1 reporter-positive cells by X-gal histochemistry (Fig. 1), X-gal staining decreased by P7 when reporter expression peaks. Hence, the normal generation of Isl1 reporter cells can only be inferred from pan-bipolar marker expression and $\mathrm{BrdU}$ incorporation at time points relevant to bipolar cell genesis. Given the lack of evidence for failed bipolar cell genesis or death, nascent bipolars may instead be diverted to alternative cell fates in the absence of Isl1. Loss of reporter expression precludes transient fate-mapping experiments that can document switches in cell fate (Inoue et al., 2002). However, numbers of other cell types were not significantly increased. Some, such as Müller cells, were decreased, whereas rod phoreceptors were not significantly affected (supplemental Fig. 2, available at www.jneurosci.org as supplemental material). Given the reduced body size of Isl1-null mice and the large number of rod photoreceptors, we are unable to rule out the possibility that a fraction of bipolar cells are diverted to rods. Indeed, recent work demonstrates that disrupting Chx10 expression favors the development of rods at the expense of bipolars (Livne-Bar et al., 2006). The precise fate of Isll-null bipolar progenitors may require analyzing the specific lineage of those cells using bipolar-specific Cre lines capable of deleting Isll early in bipolar cell development while reporting on their fate into maturity. Results of BrdU pulse labeling experiments spanning P3 to P12 suggest that Isl1-null retinal progenitors that incorporated BrdU during a time of peak bipolar cell genesis (P3) are significantly more biased to the ONL instead of the INL (supplemental Fig. 9, available at www.jneurosci.org as supplemental material) $\left(\chi^{2}=9.31,1 ; n=6 ; p<0.01\right)$. Thus, INL defects in Isl1-null retinas might arise from a switch in fate of bipolar progenitors to cell fates within the ONL.

Isl1-null retinas are, in fact, chimeras, wherein the development of wild type cells can be assessed in an otherwise Isl1-null environment to test whether the phenotype observed after Isll disruption is cell autonomous or non-cell autonomous. By exploiting the mosaic pattern of Isl1 deletion using the Six3-cre line, we found that residual Isl1-expressing cells often colocalized with residual markers of pan-bipolar cell identity (Chx10) (supplemental Fig. 5, available at www.jneurosci.org as supplemental material), of ON-bipolar cells $(\mathrm{Go} \alpha)$ (supplemental Fig. 5, available at www.jneurosci.org as supplemental material) and of rod bipolar cells (Prkca) (Fig. 3). A mosaic pattern of deletion cannot be exploited to evaluate whether the role of Isl1 in OFF-bipolar cells is cell autonomous, because OFF-bipolar cells do not maintain their expression of Isl1 into adulthood (Fig. 5). In contrast, the colocalization of Isl1 and Bhlhb5 in presumptive OFF-bipolar cells within the INL at P6 suggests that Isl1 is expressed in at least a proportion of OFF-bipolar cells. 
Although RGC-derived factors are important for retinal development (Wang et al., 2005), unaltered bipolar subtype development in Pou4f2-null mice suggests that the bipolar phenotype observed in Isl1nulls is unlikely to be a consequence of the preceding RGC loss (Figs. 2-4 and supplemental Fig. 4, available at www.jneurosci.org as supplemental material). Incidentally, even in models of more severe RGC loss, beyond the level observed in Isl1-null mice (Fig. 1 and supplemental Fig. 2, available at www.jneurosci.org as supplemental material), the bipolar cell phenotype measured both by ERG (Fig. 7) and bipolar cell marker expression is less severe than in Isl1-nulls (Figs. 2-4) (Brzezinski et al., 2005; Mu et al., 2005).

The precise functions of Isl1 in bipolar cell genesis are unknown, because transcriptional targets in the retina have not been identified. Considering that the emergence of pan-bipolar marker expression appears initially unchanged in the Isl1-null retina, Isl1 may function in the events after the specification of general bipolar cell identity. Such events may include the specification of bipolar cell subtype or the differentiation of previously specified bipolar subtypes (supplemental Fig. 10, available at www.jneurosci.org as supplemental material). The uncertainty here stems from the uncertainty regarding when bipolar cells become committed to distinct subtypes. In part, Isl1 may function through the regulation of bipolar subtype-specific transcription factors, such as Bhlhb4 and Vsx1. Consistent with this, bipolar cell defects in the Isl1-null retina phenocopy the combined defects of the Bhlhb4- and Vsx1-null retinas. However, ON-cone bipolar cells, which are relatively preserved in the Bhlhb4- and Vsx1-null retinas, are disrupted in the absence of Isl1.

\section{Cholinergic interneurons in the retina depend on Isl1 function}

Disruption of Isl1 in the retina causes a marked reduction of cholinergic marker expression, as gauged by both ChAT and Calretinin immunohistochemistry (Fig. 6). The immunostaining pattern for Calretinin in the Isl1-null retina is analogous to that observed when cholinergic amacrine cells are ablated using a targeted immunotoxin approach (Yoshida et al., 2001), supporting a claim that cholinergic amacrines are missing in the Isl1-null retina. The expression of cholinergic transmitter phenotype in the forebrain depends on a network of Nkx and Lhx class of factors that includes Nkx2.1 (Titf1) and Lhx7 (also Lhx8) (Marin et al., 2000; Zhao et al., 2003; Fragkouli et al., 2005). Interestingly, Isl1 expression in the forebrain becomes restricted to cholinergic interneurons of the striatum as well as to several other subcortical forebrain structures (Wang and Liu, 2001), suggesting an important role for Isl1 in cholinergic neuron development among anatomically disparate sites, including the spinal cord, striatum, and retina.

\section{Isl1-null mice display marked losses of retinal and visual functions}

Isl1-null mice show profound ERG deficits with a complete absence of corneal positive b-waves. The nonexistent b-wave in
Isl1-null mice persists over a range of light intensities that has previously been shown to stimulate both rod- and conemediated responses in C57BL/6J mice (Umino et al., 2006). Isl1null mice ERGs are more severely disrupted than those recorded from the Bhlhb4-null mouse (Bramblett et al., 2004). Such diminished b-wave amplitudes are analogous to those recorded from $m$ GluR6-null mice (Masu et al., 1995), which have a disruption in ON-bipolar cell signaling. This complete loss of b-wave amplitude in response to short flashes supports the assertion that Isl1 is required for the differentiation of most rod and ON-cone bipolar cells. Indeed, the disruption of rod-to-rod bipolar synapses (Fig. 3) underscores the role of Isl1 in rod bipolar development.

The significant losses in visual function seen in Isl1-null mice are likely a composite of retinal defects found at multiple levels of the retinal circuitry. Among the key defects possibly underlying this deficit are the losses in functional bipolar cells, cholinergic amacrines, and RGCs. Visual function is clearly disrupted when ON-bipolar cell function is jeopardized (Iwakabe et al., 1997), as well as when cholinergic amacrines are ablated (Yoshida et al., 2001). Cholinergic amacrines have a unique role in conferring directionally sensitive responses onto RGCs for visuomotor reflexes; in fact, even disruption of this cell type alone can diminish visuomotor performance (Yoshida et al., 2001). The loss of vision in Isl1-null mice is consistent with the specific cell-type deficits observed histologically.

Furthermore, Isl1 expression is maintained in the adult retina in a cell type-restricted manner, where it may have a role in maintaining the function of such cell types. Assessing optomotor behaviors and ERGs after disrupting Isll in the adult retina will determine whether Isl1 has a role in the function of the adult retina.

\section{References}

Blackshaw S, Harpavat S, Trimarchi J, Cai L, Huang H, Kuo WP, Weber G, Lee K, Fraioli RE, Cho SH, Yung R, Asch E, Ohno-Machado L, Wong WH, Cepko CL (2004) Genomic analysis of mouse retinal development. PLoS Biol 2:E247.

Bramblett DE, Pennesi ME, Wu SM, Tsai MJ (2004) The transcription fac- 
tor Bhlhb4 is required for rod bipolar cell maturation. Neuron 43:779-793.

Brzezinski IV JA, Brown NL, Tanikawa A, Bush RA, Sieving PA, Vitaterna MH, Takahashi JS, Glaser T (2005) Loss of circadian photoentrainment and abnormal retinal electrophysiology in Math5 mutant mice. Invest Ophthalmol Vis Sci 46:2540-2551.

Burmeister M, Novak J, Liang MY, Basu S, Ploder L, Hawes NL, Vidgen D, Hoover F, Goldman D, Kalnins VI, Roderick TH, Taylor BA, Hankin MH, McInnes RR (1996) Ocular retardation mouse caused by Chx10 homeobox null allele: impaired retinal progenitor proliferation and bipolar cell differentiation. Nat Genet 12:376-384.

Cheng CW, Chow RL, Lebel M, Sakuma R, Cheung HO, Thanabalasingham V, Zhang X, Bruneau BG, Birch DG, Hui CC, McInnes RR, Cheng SH (2005) The Iroquois homeobox gene, Irx5, is required for retinal cone bipolar cell development. Dev Biol 287:48-60.

Chow RL, Snow B, Novak J, Looser J, Freund C, Vidgen D, Ploder L, McInnes RR (2001) Vsx1, a rapidly evolving paired-like homeobox gene expressed in cone bipolar cells. Mech Dev 109:315-322.

Chow RL, Volgyi B, Szilard RK, Ng D, McKerlie C, Bloomfield SA, Birch DG, McInnes RR (2004) Control of late off-center cone bipolar cell differentiation and visual signaling by the homeobox gene Vsxl. Proc Natl Acad Sci USA 101:1754-1759.

Cuenca N, Fernandez E, Kolb H (1990) Distribution of immunoreactivity to protein kinase $\mathrm{C}$ in the turtle retina. Brain Res 532:278-287.

Dyer MA, Cepko CL (2001) p27Kip1 and p57Kip2 regulate proliferation in distinct retinal progenitor cell populations. J Neurosci 21:4259-4271.

Dyer MA, Livesey FJ, Cepko CL, Oliver G (2003) Prox1 function controls progenitor cell proliferation and horizontal cell genesis in the mammalian retina. Nat Genet 34:53-58.

Elshatory Y, Deng M, Xie X, Gan L (2007) Expression of the LIMhomeodomain protein Isl1 in the developing and mature mouse retina. J Comp Neurol 503:182-197.

Feng L, Xie X, Joshi P, Yang Z, Shibasaki K, Chow R, Gan L (2006) Requirement for Bhlhb5 in the specification of amacrine and cone bipolar subtypes in mouse retina. Development 133:4815-4825.

Fragkouli A, Hearn C, Errington M, Cooke S, Grigoriou M, Bliss T, Stylianopoulou F, Pachnis V (2005) Loss of forebrain cholinergic neurons and impairment in spatial learning and memory in LHX7-deficient mice. Eur J Neurosci 21:2923-2938.

Furuta Y, Lagutin O, Hogan BL, Oliver GC (2000) Retina- and ventral forebrain-specific Cre recombinase activity in transgenic mice. Genesis 26:130-132.

Gabriel R, Witkovsky P (1998) Cholinergic, but not the rod pathway-related glycinergic (All), amacrine cells contain calretinin in the rat retina. Neurosci Lett 247:179-182.

Galli-Resta L, Resta G, Tan SS, Reese BE (1997) Mosaics of islet-1expressing amacrine cells assembled by short-range cellular interactions. J Neurosci 17:7831-7838.

Gan L, Wang SW, Huang Z, Klein WH (1999) POU domain factor Brn-3b is essential for retinal ganglion cell differentiation and survival but not for initial cell fate specification. Dev Biol 210:469-480.

Hatakeyama J, Tomita K, Inoue T, Kageyama R (2001) Roles of homeobox and bHLH genes in specification of a retinal cell type. Development 128:1313-1322.

Haverkamp S, Wassle H (2000) Immunocytochemical analysis of the mouse retina. J Comp Neurol 424:1-23.

Haverkamp S, Ghosh KK, Hirano AA, Wassle H (2003a) Immunocytochemical description of five bipolar cell types of the mouse retina. J Comp Neurol 455:463-476.

Haverkamp S, Haeseleer F, Hendrickson A (2003b) A comparison of immunocytochemical markers to identify bipolar cell types in human and monkey retina. Vis Neurosci 20:589-600.

Inoue T, Hojo M, Bessho Y, Tano Y, Lee JE, Kageyama R (2002) Math3 and NeuroD regulate amacrine cell fate specification in the retina. Development 129:831-842.

Iwakabe H, Katsuura G, Ishibashi C, Nakanishi S (1997) Impairment of pupillary responses and optokinetic nystagmus in the mGluR6-deficient mouse. Neuropharmacology 36:135-143.

Kondo H, Kuramoto H, Wainer BH, Yanaihara N (1985) Discrete distribution of cholinergic and vasoactive intestinal polypeptidergic amacrine cells in the rat retina. Neurosci Lett 54:213-218.

Li JY, Joyner AL (2001) Otx2 and Gbx2 are required for refinement and not induction of mid-hindbrain gene expression. Development 128:4979-4991.

Li S, Mo Z, Yang X, Price SM, Shen MM, Xiang M (2004) Foxn4 controls the genesis of amacrine and horizontal cells by retinal progenitors. Neuron 43:795-807.

Lin B, Wang SW, Masland RH (2004) Retinal ganglion cell type, size, and spacing can be specified independent of homotypic dendritic contacts. Neuron 43:475-485.

Livne-Bar I, Pacal M, Cheung MC, Hankin M, Trogadis J, Chen D, Dorval KM, Bremner R (2006) Chx10 is required to block photoreceptor differentiation but is dispensable for progenitor proliferation in the postnatal retina. Proc Natl Acad Sci USA 103:4988-4993.

Marin O, Anderson SA, Rubenstein JL (2000) Origin and molecular specification of striatal interneurons. J Neurosci 20:6063-6076.

Marquardt T, Ashery-Padan R, Andrejewski N, Scardigli R, Guillemot F, Gruss $\mathrm{P}$ (2001) Pax6 is required for the multipotent state of retinal progenitor cells. Cell 105:43-55.

Masland RH (2001) Neuronal diversity in the retina. Curr Opin Neurobiol 11:431-436.

Masu M, Iwakabe H, Tagawa Y, Miyoshi T, Yamashita M, Fukuda Y, Sasaki H, Hiroi K, Nakamura Y, Shigemoto R, Takada M, Nakamura K, Nakao K, Katsuki M, Nakanishi S (1995) Specific deficit of the ON response in visual transmission by targeted disruption of the mGluR6 gene. Cell 80:757-765.

Milam AH, Dacey DM, Dizhoor AM (1993) Recoverin immunoreactivity in mammalian cone bipolar cells. Vis Neurosci 10:1-12.

Mimura Y, Mogi K, Kawano M, Fukui Y, Takeda J, Nogami H, Hisano S (2002) Differential expression of two distinct vesicular glutamate transporters in the rat retina. NeuroReport 13:1925-1928.

Mu X, Fu X, Sun H, Liang S, Maeda H, Frishman LJ, Klein WH (2005) Ganglion cells are required for normal progenitor- cell proliferation but not cell-fate determination or patterning in the developing mouse retina. Curr Biol 15:525-530.

Ohtoshi A, Wang SW, Maeda H, Saszik SM, Frishman LJ, Klein WH, Behringer RR (2004) Regulation of retinal cone bipolar cell differentiation and photopic vision by the CVC homeobox gene Vsxl. Curr Biol 14:530-536.

Pasteels B, Rogers J, Blachier F, Pochet R (1990) Calbindin and calretinin localization in retina from different species. Vis Neurosci 5:1-16.

Pfaff SL, Mendelsohn M, Stewart CL, Edlund T, Jessell TM (1996) Requirement for LIM homeobox gene Isl1 in motor neuron generation reveals a motor neuron-dependent step in interneuron differentiation. Cell 84:309-320.

Pochet R, Pasteels B, Seto-Ohshima A, Bastianelli E, Kitajima S, Van Eldik LJ (1991) Calmodulin and calbindin localization in retina from six vertebrate species. J Comp Neurol 314:750-762.

Rodriguez CI, Buchholz F, Galloway J, Sequerra R, Kasper J, Ayala R, Stewart AF, Dymecki SM (2000) High-efficiency deleter mice show that FLPe is an alternative to Cre-loxP. Nat Genet 25:139-140.

Sharma K, Sheng HZ, Lettieri K, Li H, Karavanov A, Potter S, Westphal H, Pfaff SL (1998) LIM homeodomain factors Lhx3 and Lhx4 assign subtype identities for motor neurons. Cell 95:817-828.

Sherry DM, Wang MM, Bates J, Frishman LJ (2003) Expression of vesicular glutamate transporter 1 in the mouse retina reveals temporal ordering in development of rod vs. cone and ON vs. OFF circuits. J Comp Neurol 465:480-498.

Thaler JP, Lee SK, Jurata LW, Gill GN, Pfaff SL (2002) LIM factor Lhx3 contributes to the specification of motor neuron and interneuron identity through cell-type-specific protein-protein interactions. Cell 110:237-249.

Tsuchida T, Ensini M, Morton SB, Baldassare M, Edlund T, Jessell TM, Pfaff SL (1994) Topographic organization of embryonic motor neurons defined by expression of LIM homeobox genes. Cell 79:957-970.

Umino Y, Frio B, Abbasi M, Barlow R (2006a) A two-alternative, forced choice method for assessing mouse vision. Adv Exp Med Biol 572:169-172.

Umino Y, Everhart D, Solessio E, Cusato K, Pan JC, Nguyen TH, Brown ET, Hafler R, Frio BA, Knox BE, Engbretson GA, Haeri M, Cui L, Glenn AS, Charron MJ, Barlow RB (2006b) Hypoglycemia leads to age-related loss of vision. Proc Natl Acad Sci USA 103:19541-19545.

Vardi N (1998) Alpha subunit of Go localizes in the dendritic tips of ON bipolar cells. J Comp Neurol 395:43-52. 
Vardi N, Matesic DF, Manning DR, Liebman PA, Sterling P (1993) Identification of a G-protein in depolarizing rod bipolar cells. Vis Neurosci 10:473-478.

Wang HF, Liu FC (2001) Developmental restriction of the LIM homeodomain transcription factor Islet-1 expression to cholinergic neurons in the rat striatum. Neuroscience 103:999-1016.

Wang SW, Kim BS, Ding K, Wang H, Sun D, Johnson RL, Klein WH, Gan L (2001) Requirement for math 5 in the development of retinal ganglion cells. Genes Dev 15:24-29.

Wang Y, Dakubo GD, Thurig S, Mazerolle CJ, Wallace VA (2005) Retinal ganglion cell-derived sonic hedgehog locally controls proliferation and the timing of RGC development in the embryonic mouse retina. Development 132:5103-5113.
Xiang M, Zhou L, Macke JP, Yoshioka T, Hendry SH, Eddy RL, Shows TB, Nathans J (1995) The Brn-3 family of POU-domain factors: primary structure, binding specificity, and expression in subsets of retinal ganglion cells and somatosensory neurons. J Neurosci 15:4762-4785.

Yoshida K, Watanabe D, Ishikane H, Tachibana M, Pastan I, Nakanishi S (2001) A key role of starburst amacrine cells in originating retinal directional selectivity and optokinetic eye movement. Neuron 30:771-780.

Young RW (1985) Cell differentiation in the retina of the mouse. Anat Rec 212:199-205.

Zhao Y, Marin O, Hermesz E, Powell A, Flames N, Palkovits M, Rubenstein JL, Westphal H (2003) The LIM-homeobox gene Lhx8 is required for the development of many cholinergic neurons in the mouse forebrain. Proc Natl Acad Sci USA 100:9005-9010. 